\title{
Kinetic Approaches to Understanding the Mechanisms of Fidelity of the Herpes Simplex Virus Type 1 DNA Polymerase
}

\author{
Yali Zhu, ${ }^{1}$ Jason Stroud, ${ }^{2}$ Liping Song, ${ }^{1}$ and Deborah S. Parris ${ }^{1,2}$ \\ ${ }^{1}$ Department of Molecular Virology, Immunology, and Medical Genetics, The Ohio State University, 2198 Graves Hall, \\ 333 West Tenth Avenue, Columbus, OH 43210, USA \\ ${ }^{2}$ Department of Molecular Genetics, The Ohio State University, 2198 Graves Hall, 333 West Tenth Avenue, Columbus, \\ OH 43210, USA \\ Correspondence should be addressed to Deborah S. Parris, parris.1@osu.edu
}

Received 17 June 2010; Revised 13 August 2010; Accepted 30 September 2010

Academic Editor: Ashis Basu

Copyright () 2010 Yali Zhu et al. This is an open access article distributed under the Creative Commons Attribution License, which permits unrestricted use, distribution, and reproduction in any medium, provided the original work is properly cited.

We discuss how the results of presteady-state and steady-state kinetic analysis of the polymerizing and excision activities of herpes simplex virus type 1 (HSV-1) DNA polymerase have led to a better understanding of the mechanisms controlling fidelity of this important model replication polymerase. Despite a poorer misincorporation frequency compared to other replicative polymerases with intrinsic $3^{\prime}$ to $5^{\prime}$ exonuclease (exo) activity, HSV-1 DNA replication fidelity is enhanced by a high kinetic barrier to extending a primer/template containing a mismatch or abasic lesion and by the dynamic ability of the polymerase to switch the primer terminus between the exo and polymerizing active sites. The HSV-1 polymerase with a catalytically inactivated exo activity possesses reduced rates of primer switching and fails to support productive replication, suggesting a novel means to target polymerase for replication inhibition.

\section{Introduction and Overview}

Maintaining fidelity of DNA replication is essential to the survival of even the simplest organisms. Based on mammalian models, lack of faithful DNA replication by DNA polymerases is associated with a large number of human diseases including, but not limited to, cancer and a variety of precancerous conditions [1-7]. A number of repair mechanisms exist to correct errors that occur during DNA synthesis, including mismatch repair, base and nucleotide excision repair, and recombination repair, and these mechanisms have been reviewed recently elsewhere [8-11]. Despite the existence of these repair mechanisms, a major determinant of replication fidelity is the ability of the replicative DNA polymerase to faithfully copy DNA. This ability is promoted not only by the high fidelity with which the polymerase selects correct versus incorrect nucleotide, but also by the reduced capacity for the polymerase to extend or replicate through primer/templates $(\mathrm{P} / \mathrm{Ts})$ containing distortions such as mismatches, abasic (AP) sites, or oxidative or bulky lesions [12-17]. This kinetic barrier to extension causes the replicative polymerase to stall. In many organisms, including prokaryotes, archea, and eukaryotes, stalling of the replicative polymerase is required to permit a short-term exchange with a low-fidelity polymerase (including one or more Yfamily polymerases, or the B-family DNA polymerase $\zeta$ ). This occurs via exclusive interactions of the respective polymerases with processivity factor in order to permit lesion bypass [18-27]. Although these lesion bypass polymerases are generally more error-prone and do not repair the lesion, they rescue the organism from lethal replication failure when DNA is damaged $[28,29]$. The stalling of a replicative polymerase at DNA lesions or following misincorporation also appears to be important for self-correction by allowing engagement of the intrinsic $3^{\prime}$ to $5^{\prime}$ exonuclease (exo) activity to "proof-read" replication errors as they occur or to sense the presence of DNA lesions [14, 30-37]. Pre-steady-state and steady-state kinetic analysis of polymerases with or without a functional exo activity have been instrumental in understanding the mechanisms that permit DNA polymerases to copy DNA with high fidelity, as well as how they 
avoid the permanent mutagenic effects of misincorporated nucleotides or DNA damage [14, 15, 33, 34, 38-40].

This review analyzes the different mechanisms that control replication fidelity that are intrinsic to replicative DNA polymerases, with a specific focus on those that are utilized by the polymerase encoded by herpes simplex virus type 1 (HSV-1) — the prototypic member of a family of viruses which cause high morbidity in the human population. Because of the ease with which they can be genetically manipulated, viruses have also proven to be excellent models to better understand the functions required for faithful genome duplication [41-45]. Moreover, viral polymerases, including the HSV-1 DNA polymerase and the human immunodeficiency virus (HIV) reverse transcriptase, are important therapeutic targets of antiviral drugs [46-48]. A summary of studies that have reported the pre-steadystate and steady-state kinetics of HSV-1 DNA polymerase are provided and compared to those of other replicative polymerases to gain insight into the similarities and differences by which these polymerases control fidelity. By understanding how activities required for high-fidelity DNA replication are modulated and coordinated by the HSV-1 DNA polymerase, it may be possible to design novel antiviral approaches to thwart replication of this important human pathogen.

\section{General Parameters that Control Polymerase Fidelity}

2.1. Nucleotide Selectivity. The single most important contributor to fidelity of most DNA polymerases is nucleotide selectivity-that is, the propensity with which the polymerase incorporates correctly versus incorrectly base-paired nucleotide [33, 34, 38, 49-53]. For replicative polymerases, nucleotide selectivity has been shown to account for an error rate in the range of $>10^{-3}$ to $10^{-5}[33,34,49$, 52]. The structures of a variety of replicative DNA polymerases have been solved, including the structures for the A-type polymerases that replicate T7 bacteriophage [54] and mammalian mitochondria (pol $\gamma$; [55]), and the Btype replicative polymerases of the T4-related bacteriophage RB69 [56], HSV-1 [57], and yeast (Saccharomyces cerevisiae) DNA polymerase $\delta$ [58]. It is clear that the nucleotidebinding pocket is able to accommodate or snuggly "fit" the correctly paired nucleotide via space and geometry $[59,60]$. This promotes a higher ground-state binding affinity of the correct, compared to incorrect, nucleotide. In addition, evidence points to an induced fit model, whereby the binding of correct nucleotide better promotes the conformational change necessary to form the closed structure required for catalysis $[34,49,50,54,56,61]$. For the bulk of these polymerases, it is this conformational change, rather than the chemical catalytic step, which is rate-limiting for correct nucleotide incorporation under pre-steady-state conditions [34, 39, 62-64]. For incorrect nucleotide incorporation, there may be contributions from conformational and chemical steps as well as from the propensity for rapid dissociation of mispaired dNTP from the polymerase [65]. By contrast, the structure of the active site of the Y-family polymerases reveals that the relatively high frequency for mismatch incorporation $\left(>10^{-3}\right)$ and for bypass of DNA lesions can be attributed to a more open active site than that formed by $A$ or B type polymerases [66-69].

2.2. Proofreading by $3^{\prime}-5^{\prime}$ Exonuclease Activity. Most replicative polymerases possess or are closely associated with a $3^{\prime}$ to $5^{\prime}$ exo activity, and loss of this inherent or associated activity results in an increased mutation frequency in vitro and in vivo [70-74]. The contribution of the exo activity to increasing overall fidelity of DNA replication varies for different sequence contexts, but is on the order of 10- to 100-fold for most of the replicative polymerases [31, 33, 51, 63, 75, 76]. The importance of polymerase-associated exo activity in maintaining genomic stability in higher eukaryotes is also confirmed by the increased cancer incidence in transgenic mice containing an exo-deficient polymerase $\delta[5,6]$ and by the premature aging that occurs in transgenic mice containing an exo-deficient pol $\gamma[3]$.

Because the exo activity competes with the polymerizing activity for the $3^{\prime}$ primer terminus, high-fidelity replication in its presence might be expected to have a real cost in terms of polymerizing speed and/or efficiency. However, pre-steady-state kinetic experiments have demonstrated that the means by which both rapid polymerization and correct nucleotide incorporation can be maintained reflects the ability of a polymerase to partition the primer terminus to the polymerizing or exo sites as needed $[15,31,33,34$, $62,63,77]$. The relative efficiencies for polymerization and proofreading during active DNA synthesis are influenced by a variety of parameters, including the relative affinities of a matched or mismatched primer terminus for the polymerizing or exo site, the rates of polymerization at matched versus mismatched primer termini, the rates of excision of matched versus mismatched primer termini, and the ability of a primer end to switch between the polymerizing and exo site with or without dissociation of the template from the polymerase.

Donlin and coworkers [33] demonstrated that the T7 DNA polymerase holoenzyme (with E. coli thioredoxin processivity factor) possesses the same binding affinity for matched or mismatched $\mathrm{P} / \mathrm{T}$ although the $\mathrm{T} 7$ pol binds $\mathrm{P} / \mathrm{T}$ tighter to the polymerization domain than to the exo site. In addition, the polymerization rate of incorporation of correct nucleotides is fast $(300 / \mathrm{sec})$ and the excision rate on ssDNA is even faster $(>700 / \mathrm{sec})[33,62]$. However, transfer of the primer to the physically distinct exo site is slower by 10 -fold when the DNA is matched compared to when it is mismatched. When a misincorporation event occurs, the polymerization rate for T7 polymerase is slowed, permitting a transfer of the primer strand from the pol to the exo site. The rapid transfer of the mismatched nucleotide to the exo site permits excision of that nucleotide. For the T7 holoenzyme, the transfer of the now-matched P/T back to the polymerization site occurs without dissociation. Thus, the kinetic partitioning of the primer between the polymerizing and exo sites, without a rate-limiting dissociation of 
TABLE 1: Summary of presteady-state kinetics of nucleotide incorporation by HSV-1 DNA polymerase.

\begin{tabular}{|c|c|c|c|c|c|}
\hline Enzyme & $\begin{array}{l}\text { Primer/template } \\
\text { end after incorp. }\end{array}$ & dNTP:Template $\mathrm{N}^{\mathrm{a}}$ & $\mathrm{k}_{\mathrm{pol}}\left(\sec ^{-1}\right)^{\mathrm{b}}$ & $\begin{array}{l}K_{\mathrm{d}}(\mathrm{dNTP}) \\
\operatorname{apparent}(\mu \mathrm{M})^{\mathrm{c}}\end{array}$ & $\begin{array}{l}\text { Efficiency }\left(\mu \mathrm{M}^{-1}\right. \\
\left.\sec ^{-1}\right)(\text { inverse rel. discrim })^{\mathrm{d}}\end{array}$ \\
\hline \multirow{4}{*}{ WT pol } & \multirow[t]{2}{*}{ Matched } & dATP:dT & $\begin{array}{l}258 \pm 38^{\mathrm{h}, \mathrm{j}} \\
\text { (estimated) }\end{array}$ & $\mathrm{ND}^{\mathrm{e}}$ & ND \\
\hline & & dTTP:dA & $157 \pm 31^{\mathrm{f}}$ & $12.2 \pm 5.7^{\mathrm{f}}$ & $12.9 \pm 2.5$ \\
\hline & Mismatched & dATP:dA & $106 \pm 9^{f}$ & $279 \pm 83^{f}$ & $0.38 \pm 0.03(34)$ \\
\hline & Abasic & dATP:Sp[0] & $209 \pm 33^{\mathrm{h}}$ & $75 \pm 37^{\mathrm{h}}$ & $2.8 \pm 0.44(4.6)$ \\
\hline \multirow[t]{2}{*}{$\mathrm{Exo}^{-}$pol } & Matched & dTTP:dA & $199 \pm 26^{\mathrm{i}}$ & $4.8 \pm 2.1^{\mathrm{i}}$ & $41.5 \pm 5.4$ \\
\hline & Mismatched & dATP:dA & $8.7 \pm 0.5^{\mathrm{j}}$ & $131 \pm 24^{j}$ & $0.07 \pm 0.004(600)$ \\
\hline WT & Matched & dATP:dT & $\begin{array}{l}261 \pm 26^{\mathrm{f}} \\
(\text { estimated) }\end{array}$ & $\mathrm{ND}$ & $\mathrm{ND}$ \\
\hline \multirow[t]{2}{*}{ pol/UL42 } & & dTTP:dA & $137 \pm 21^{\mathrm{f}}$ & $6.4+2.8^{f}$ & $21.4 \pm 3.3$ \\
\hline & Mismatched & dATP:dA & $37 \pm 4^{\mathrm{f}}$ & $229+89^{f}$ & $0.16 \pm 0.02(130)$ \\
\hline $\mathrm{Exo}^{-}$ & Matched & dGTP:dC & $\begin{array}{l}640 \pm 60^{\mathrm{g}} \\
\text { (estimated) }\end{array}$ & $8 \pm 2^{g}$ & $80 \pm 7.5$ \\
\hline $\mathrm{pol} / \mathrm{UL} 42$ & Chain term & ACV-TP:dC & $10.1 \pm 0.8^{\mathrm{g}}$ & $6 \pm 1^{\mathrm{g}}$ & $1.7 \pm 0.3(48)$ \\
\hline
\end{tabular}

${ }^{a}$ Refers to incoming dNTP for incorporation opposite the templating residue $(\mathrm{N})$ indicated. ${ }^{\mathrm{b}}$ Rate constant at unlimiting incoming dNTP concentration determined by the equation $k_{\mathrm{obs}}=k_{\mathrm{pol}}[\mathrm{dNTP}] /\left([\mathrm{dNTP}]+K_{\mathrm{d}}\right) .{ }^{\mathrm{c}}$ Apparent ground-state dissociation constant of dNTP determined according to the function indicated above. ${ }^{\mathrm{d} E f f i c i e n c y}$ for incorporation of dNTP was calculated as $k_{\mathrm{pol}} / K_{\mathrm{d}}(\mathrm{dNTP})$. Relative discrimination was estimated by dividing the efficiency for formation of a matched terminus by that for formation of mismatched, abasic, or chain terminator (acyclovir triphosphater, ACV-TP) primer/template interface. Number shown in parentheses is inverse of relative discrimination for formation of that terminus. ${ }^{e}$ Not Done (ND). ${ }^{f}$ From [64]. ${ }^{\mathrm{g}}$ From [78]. ${ }^{\text {h}}$ From [79]. ${ }^{\mathrm{i}}$ From [75]. ${ }^{\mathrm{j}}$ From [80]

the holoenzyme from the $\mathrm{P} / \mathrm{T}$, permits rapid repair with little cost to overall rate of extension [33].

The structurally similar A-type mitochondrial polymerase (pol $\gamma$ ) possesses an inherently poorer fidelity than the T7 polymerase $[31,63]$. Compared to T7 polymerase, excision of mismatched DNA occurs at a much slower maximum rate $(9 / \mathrm{sec})$. Nevertheless, error correction without enzyme dissociation occurs with an efficiency of $80 \%$ [31]. By contrast, another A-type enzyme, Klenow fragment of DNA polymerase I, has an even slower rate of excision $(0.003 / \mathrm{sec})$, which would favor dissociation when that enzyme stalls at a mismatch $[15,77]$. The latter results suggest that proofreading by Klenow is a less efficient means for error correction than by either bacteriophage T7 DNA polymerase or mammalian pol $\gamma$.

The T4 DNA polymerase catalytic subunit (a B-type polymerase) also incorporates correct nucleotides at a rapid rate $(>400 / \mathrm{sec})$ whereas the exo activity excises ssDNA at a rate of approximately 100/sec [34]. As for the T7 polymerase, transfer of primer from the polymerization to the exo site is slower (5-fold for T4 polymerase) for matched compared to mismatched P/T. However, because the rate constant for dissociation of the T4 polymerase catalytic subunit from the $\mathrm{P} / \mathrm{T}(6-8 / \mathrm{sec})$ competes with that for transfer of a mismatched primer to the exo site $(5 / \mathrm{sec})$, direct editing can occur only $40 \%$ of the time. Therefore, editing by the T4 polymerase catalytic subunit is less efficient than by the T7 DNA polymerase holoenzyme [33, 34].

As shown for the T4-like RB69 bacteriophage DNA polymerase, the ability of a mispaired end to access the exo site requires a $\sim 40^{\circ}$ rotation relative to its position at the polymerase active site $[56,81]$. Because the template strand is not firmly anchored during this movement to the exo site for Klenow enzyme, the DNA must diffuse to the exo site, although one-way diffusion could be facilitated by retention of the primer in the thumb domain during the conformational change $[56,82]$. A $\beta$-hairpin within the exo domain of the B-type polymerase encoded by bacteriophage RB69 has been proposed to hold the template in place as the primer terminus is transferred from the polymerizing to the exo active sites [83]. The analogous hairpin of S. cerevisiae pol $\delta$ interacts extensively with the template strand which could stabilize the enzyme-DNA interaction during the conformational transition [58]. By contrast, the $\beta$-hairpin of RB69 polymerase does not associate with normal DNA and interacts with only a portion of the ssDNA template containing an abasic site [56, 58]. This could account for the relative inefficiency by which the RB69-like T4 DNA polymerase can edit mismatched DNA in a single association event $[34,58,84]$.

2.3. Alternative Mechanisms by Which the Exo Activity Enhances Polymerase Fidelity. It is becoming increasingly clear that the exo activity associated with polymerases increases fidelity by mechanisms in addition to nucleotide editing. For example, the presence of exo activity also appears to be important for preventing translesion DNA synthesis or strand displacement synthesis by a number of polymerases, including those of pol $\delta$, bacteriophage T4, and HSV-1 [14, 85-89]. This is because the ability of a polymerase to partition the DNA primer between the polymerizing and exo sites allows the enzyme to engage in idling turnover-that is, successive rounds of excision and incorporation, with or without dissociation-whenever 


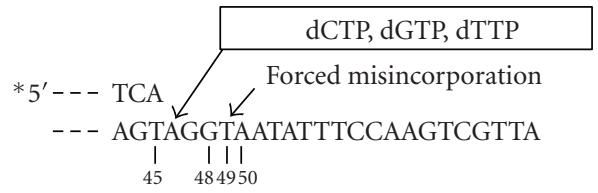

(a)

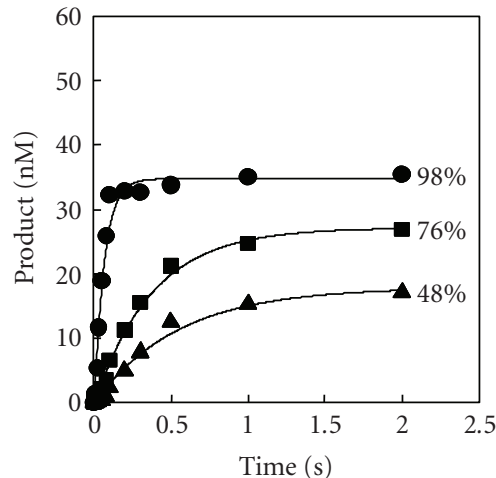

(b) Wild-type pol

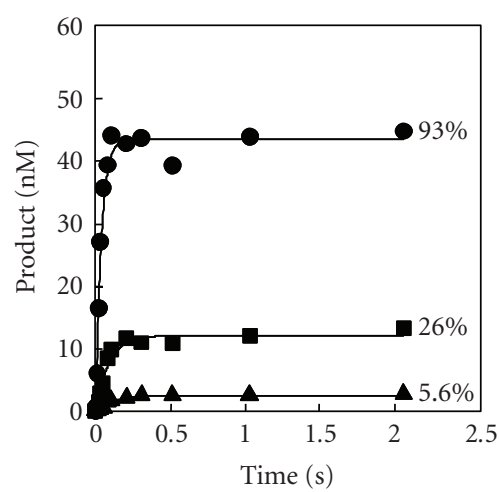

(d) Wild-type pol/UL42

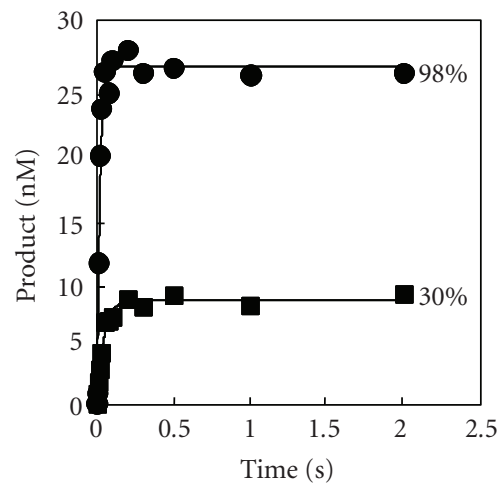

(g) Wild-type pol

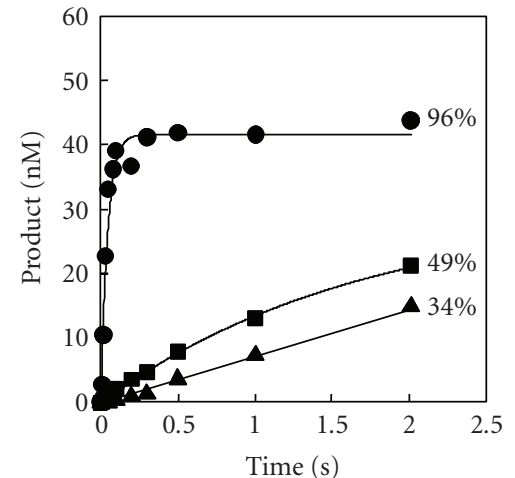

(c) $\mathrm{Exo}^{-} \mathrm{pol}$

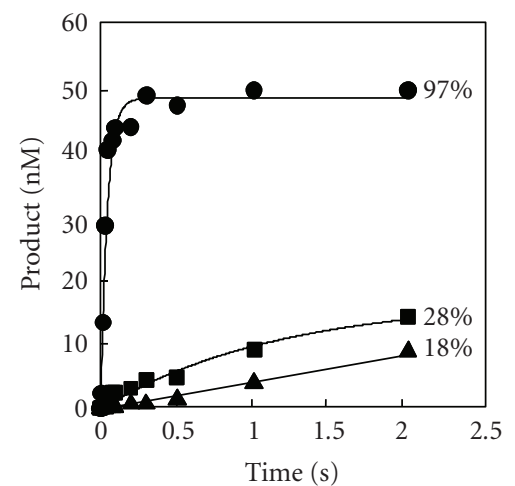

(e) $\mathrm{Exo}^{-} \mathrm{pol} / \mathrm{UL} 42$

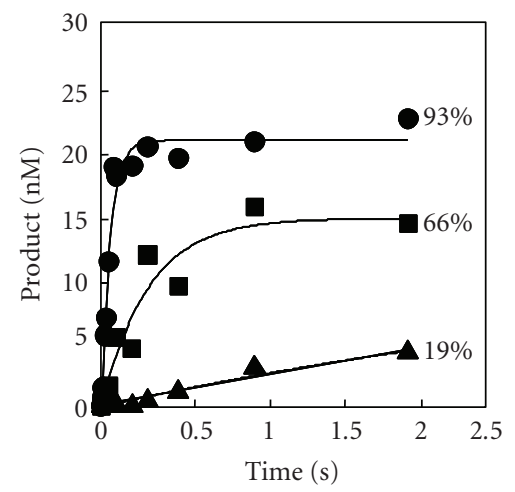

(h) $\mathrm{Exo}^{-}$pol

Figure 1: Running-start single-turnover kinetics for extension of mismatched or damaged P/Ts by HSV-1 DNA polymerase. Panels (a)(e) represent forced misincorporation and extension reactions and are adapted from [75] whereas panels (f)-(h) show extension of APcontaining $\mathrm{P} / \mathrm{Ts}$ and are adapted from [79]. (a) A partial sequence of the P/T (5' end-labeled $45 \mathrm{nt}$ primer annealed to $67 \mathrm{nt}$ template) is shown. The dNTPs added lacked dATP to force misincorporation opposite position 49 in reactions containing the wild-type pol (b), exo ${ }^{-}$ pol (c), wild-type pol/UL42 (d), or exo- pol/UL42 (e). Reactions were performed with $50 \mathrm{nM}$ enzyme, $100 \mathrm{nM} \mathrm{P/T}$, and $250 \mu \mathrm{M}$ of each dNTP indicated and single-turnover conditions were ensured by the addition of nonradioactive activated calf-thymus DNA trap (500 $\mu \mathrm{g} / \mathrm{ml})$ at the time of initiation. Reactions were terminated by the addition of EDTA, products were separated on denaturing polyacrylamide gels, gels were exposed to storage phosphor screens, and bands were quantified as previously described [75, 79]. (b)-(e) show plots of the concentration of products formed greater than or equal to $48(\mathbf{O}), 49(\mathbf{\square})$, or $50(\mathbf{\Delta})$ nt in length. Except as indicated, the data were fit to the burst equation [extension product] $=A\left(1-e^{-k t}\right)$, where $A$ is the burst amplitude, $k$ is the observed rate constant, and $t$ is the reaction time. The plots for formation of $50 \mathrm{nt}$ product by the $\mathrm{exo}^{-}$pol or exo $\mathrm{pol}^{-} \mathrm{UL} 42$ were produced by fitting the data to a linear function. The percentages next to each curve represent the amounts of primer $\geq$ to that length compared to the amount of $\mathrm{P} / \mathrm{T}$ actively engaged by the respective polymerases (i.e., that were extended by at least $1 \mathrm{nt}$ ). (f) A partial sequence of the P/T is shown. A dSpacer ( $\mathrm{dSp}$ ) was placed at position 46 from the $3^{\prime}$ end of the template to mimic an abasic site. Reactions were performed as indicated above except that all four dNTPs were included for extension by wild-type pol (g) or exo ${ }^{-}$pol (h). Products representing primers extended to position 45 located $1 \mathrm{nt}$ upstream ( -1 ) of the AP site and beyond $(\mathbf{)})$, products extended to the AP site and beyond $(\boldsymbol{\square})$, and products that were extended 1 or more nucleotides past the AP site $(\boldsymbol{\Delta})$ are shown. The data in the plots were fit to the burst equation or to a linear function as indicated for plots (b)-(e). The numbers to the right of the curves represent the percentage of primers extended at least to this site compared to the number that were actively engaged by the respective polymerases. 
it encounters a kinetic barrier to extension. This idlingbehavior increases overall DNA replication fidelity because it prevents extension through abasic sites or oxidized nucleotides, such as 8-oxyguanine, which would have a high probability for introducing mutations [13]. Idling turnover by a polymerase also limits strand displacement synthesis. Failure to limit strand displacement synthesis by yeast pol $\delta$ during Okazaki fragment maturation has been shown to lead to the production of aberrant or improperly processed lagging strand intermediates in vitro and higher mutation frequency in vivo $[86,87]$.

2.4. Role of Processivity Factors in Fidelity of DNA Replication. There has been much disagreement concerning the role of polymerase accessory proteins in maintaining fidelity. Parameters that could be altered by processivity factors include kinetic barriers to extending a mismatch or bypassing a lesion, the ability of the polymerase to partition its activity between the physically distinct exo and pol sites, the relative accessibility of the exo and pol sites, and dissociation of polymerase upon encountering a barrier to extension [33, $72,76,90,91]$. Capson et al. [34] proposed that the T4 polymerase processivity factor would enhance fidelity by limiting the dissociation of enzyme from mismatched $\mathrm{P} / \mathrm{T}$, thereby increasing the efficiency for direct editing by the enzyme. However, for several polymerases, an inverse relationship was shown between processivity or DNA binding and fidelity, at least under some circumstances [90-93]. For T7 DNA polymerase, the processivity factor was found to enhance fidelity by retaining the polymerase long enough to edit misincorporated nucleotides [33]. For T4 DNA polymerase, the addition of processivity factors to the wild-type enzyme had no impact on fidelity of DNA replication and did not permit lesion bypass. However the addition of processivity factors to an exo-deficient T4 polymerase did permit lesion bypass with low concentrations of enzyme, which did not permit efficient translesion synthesis in the absence of processivity factors [91]. Proliferating cell nuclear antigen (PCNA) was also demonstrated to increase misinsertion frequency and to promote the ability of mammalian pol $\delta$ to bypass DNA lesions $[90,93,94]$, thereby reducing fidelity. Likewise, the addition of processivity factor to mitochondrial polymerase $(\operatorname{pol} \gamma)$ reduced the incorporation fidelity of both the wild-type and exo-deficient enzyme in gap-filling assays, predominantly by enhancing the efficiency for extending mismatches [76].

\section{Herpes Simplex Virus Type 1 as a Model Eukaryotic Replicative DNA Polymerase}

3.1. Properties of the HSV-1 DNA Polymerase. HSV-1 encodes a B-type DNA-dependent DNA polymerase that is the product of the UL30 gene and is essential for origin-dependent DNA synthesis in cell culture and for the production of infectious progeny virus in vivo [95-100]. In vitro, the HSV1 DNA polymerase is also required together with 5 other viral encoded proteins for leading strand synthesis on model templates [101]. In addition to a $5^{\prime}$ to $3^{\prime}$ polymerizing activity, the polymerase catalytic subunit (pol) possesses an intrinsic $3^{\prime}$ to $5^{\prime}$ exo domain $[57,99,102,103]$. In infected cells, HSV-1 pol forms a stable heterodimer with the product of the UL42 gene (UL42) [104-106]. The UL42 protein is a double-stranded DNA-binding protein that serves as an accessory protein to increase the processivity of the HSV1 pol catalytic subunit $[104,107,108]$. The ability of the UL42 processivity subunit to form a stable heterodimer with the HSV-1 pol catalytic subunit resembles the type of arrangement observed for the A-type polymerases, T7 bacteriophage DNA polymerase and mitochondrial pol $\gamma$, with their respective processivity factors. However, the structure of HSV-1 UL30 pol catalytic subunit most closely resembles that for the eukaryotic replicative polymerase, pol $\delta[57,58]$. Interestingly, the structure of the UL42 processivity factor resembles that for a subunit of the pol $\delta$ processivity factor, PCNA $[109,110]$. However, the two globular domains of HSV-1 UL42 are oriented differently from those of a PCNA monomer such that they could not easily form the toroidal structure of the homotrimeric PCNA processivity factor [109]. The co-crystal structure of UL42 with a pol C-terminal peptide suggests a flexible attachment to the unstructured C-terminal tail of HSV-1 pol, similar to what has been observed for other processivity factors with their cognate B-type polymerase [56-58, 81, 82, 109]. Since the UL42 processivity factor does not require energy or other proteins to load it onto DNA or to form the heterodimeric holoenzyme $[104,105,107,111]$, it is easier to investigate the role of processivity factor in controlling the fidelity of this viral replicative polymerase compared to that of its close homolog, pol $\delta$.

3.2. Genetic Analysis of HSV-1 Replication Fidelity. Epidemiological studies suggest that HSV-1 DNA replication is not as faithful as that of its human host. For example, mutations occur frequently during HSV-1 replication in vivo, such that many nucleotide polymorphisms can be observed even in epidemiologically related strains of virus [112-114]. The genetic diversity of viral progeny that results from this poor fidelity is likely to contribute to selection of virus "mutants" capable of evading natural host immune mechanisms as well as antiviral drugs. Indeed, clinical isolates from humans not exposed to antiviral drugs have been shown to contain a preexisting subpopulation of virus resistant to high concentrations of acyclovir [115]. For random HSV1 isolates from Japan, the average number of nucleotide differences observed in the 1,131 bp thymidine kinase (tk) gene was 3.3 [114]. In another study, the HSV-1 tk gene mutation frequency (estimated at $5 \times 10^{-5}$ ) was determined by measuring the average frequency of acyclovir-resistant plaques that arose under nonselective growth conditions during a single replication cycle for independent cultures of an acyclovir-sensitive (wild-type) laboratory strain of HSV-1 [116].

Examining the role of the $3^{\prime}-5^{\prime}$ exo activity in maintaining the fidelity of HSV-1 DNA replication in culture has been challenging since it has not been possible to isolate viral mutants by altering conserved residues within either 
TABLE 2: Summary of presteady-state kinetics of excision by wild-type HSV-1 polymerase.

\begin{tabular}{|c|c|c|c|c|c|}
\hline Enzyme & $\mathrm{P} / \mathrm{T}$ interface & $\begin{array}{l}\text { Fast burst rate } \\
\text { constant }\left(\sec ^{-1}\right)\end{array}$ & $\begin{array}{l}\mathrm{P} / \mathrm{T} \text { excised at fast } \\
\text { rate }(\%)\end{array}$ & $\begin{array}{l}\text { Slow burst rate } \\
\text { constant }\left(\sec ^{-1}\right)\end{array}$ & $\begin{array}{l}\mathrm{P} / \mathrm{T} \text { excised at slow } \\
\text { rate }(\%)\end{array}$ \\
\hline \multirow{3}{*}{ WT pol ${ }^{\mathrm{a}}$} & $\mathrm{dA} / \mathrm{dT}$ (matched) & $59 \pm 18^{\mathrm{b}}$ & $6^{\mathrm{b}}$ & $2.2 \pm 0.7^{b}$ & $26^{\mathrm{b}}$ \\
\hline & $\mathrm{dA} / \mathrm{dA}$ (mismatched) & $113 \pm 7^{\mathrm{c}}$ & $29^{c}$ & NA & NA \\
\hline & dA/AP (abasic) & $130 \pm 0^{\mathrm{c}}$ & $39^{\mathrm{c}}$ & NA & NA \\
\hline \multirow{6}{*}{ WT pol/UL42 ${ }^{\mathrm{d}}$} & $\mathrm{dG} / \mathrm{dC}$ (matched) & $12 \pm 6^{\mathrm{b}}$ & $12.5^{\mathrm{b}}$ & $0.25 \pm 0.02^{\mathrm{b}}$ & $87.5^{\mathrm{b}}$ \\
\hline & $\mathrm{dG}$ (8 nt frayed) & $125 \pm 7^{\mathrm{b}}$ & $73^{\mathrm{b}}$ & $1.3 \pm 0.2^{\mathrm{b}}$ & $27^{\mathrm{b}}$ \\
\hline & ACV/dC (matched) & $(5.1 \pm 0.4) \times 10^{-3^{c}}$ & $96^{\mathrm{c}}$ & NA & NA \\
\hline & ACV (8 nt frayed) & $\geq 0.3^{c}$ & $100^{\mathrm{c}}$ & NA & NA \\
\hline & $\mathrm{ACV} / \mathrm{dC}+\mathrm{dNTP}$ & $(2 \pm 0.6) \times 10^{-4^{c}}$ & $94^{\mathrm{c}}$ & NA & NA \\
\hline & $\begin{array}{l}\text { ACV }(8 \mathrm{nt} \text { frayed })+ \\
\text { dNTP }\end{array}$ & $\geq 0.3^{c}$ & $100^{\mathrm{c}}$ & NA & NA \\
\hline
\end{tabular}

a The wild-type pol catalytic subunit $(25 \mathrm{nM})$ was incubated in the presence of EDTA with $10 \mathrm{nM}$ of a $46 \mathrm{nt}$ primer annealed to a $67 \mathrm{nt}$ template differing only at the primer/template $(\mathrm{P} / \mathrm{T})$ interface as indicated. Single turnover conditions were achieved by initiating reactions with $\mathrm{MgCl}_{2}$ plus activated calf thymus DNA to trap dissociating pol (from [79]). All kinetic constants are apparent.

${ }^{\mathrm{b}}$ The amount of full-length primer remaining was plotted as a function of time and the data were fit to the five-parameter double exponential decay function [intact primer] $=a e^{-b t}+c e^{-d t}+f$, where $a$ and $b$ are the amplitude and burst rate constant, respectively, during the fast phase, and $c$ and $d$ are the amplitude and burst rate constant during the slow phase of excision. The $f$ constant represents the amount of unexcised primer remaining due to dissociation of the enzyme from the $\mathrm{P} / \mathrm{T}$ or to failure of the enzyme to bind all of the $\mathrm{P} / \mathrm{T}$ prior to initiation.

${ }^{\mathrm{c}}$ The amount of full-length primer remaining was plotted as a function of time and the data were fit to a three-parameter single exponential decay function [intact primer] $=a e^{-b t}+c$ due to the absence of a slower phase. NA, not applicable for single exponential functions.

${ }^{\mathrm{d}}$ The wild-type pol/UL42 heterodimer $(100 \mathrm{nM})$ was incubated in the presence of EDTA under single turnover conditions with $90 \mathrm{nM} 26 \mathrm{nt}$ primer containing the $3^{\prime}$ nucleotide dGMP (dG) or acyclovir monophosphate (ACV) annealed to a $45 \mathrm{nt}$ template prepared as described [78]. In some cases as indicated, the $\mathrm{P} / \mathrm{T}$ contained 8 mismatches at the $3^{\prime}$ end of the primer (frayed), the last of which was ACV. When added, the concentration of dNTPs was $100 \mu \mathrm{M}$ (from [78]). All kinetic constants are apparent.

the Exo I or Exo II sites [117, 118]. Most of the HSV-1 Exo II site pol mutations created by Gibbs and coworkers failed to complement the replication of a pol null virus or to synthesize any viral DNA in these complementation assays [118]. Biochemical analysis of similar Exo II mutants by another group revealed that these mutations compromised not only the exo activity, but also the extension activity of the polymerase, perhaps accounting for their lethal phenotype [119]. Mutations that map in the conserved Exo I residues that are involved in the coordination of the metal ions required for catalysis (e.g., D368A and E370A) also possess little if any exo activity, though their polymerase activities are similar to or greater than that of the wild-type HSV-1 pol $[75,119]$. Nevertheless, the D368A Exo I mutation was lethal for virus replication [117]. It has been suggested that the exo and polymerizing domains of the HSV-1 pol may be fundamentally different and less distinct from each other than those domains for other polymerases [118]. However, the resolved crystal structure of the HSV-1 pol shows that the organization of the exo domain with respect to the palm, fingers, and thumb subdomains is similar to that shown for S. cereviseae pol $\delta[57,58]$.

The only exo-deficient HSV-1 polymerases capable of supporting virus replication are those that map to the conserved Exo III site [116]. These Exo III site mutant proteins (e.g., Y577H, a double mutant Y577H/D581A, and $\mathrm{Y} 577 \mathrm{~F}$ ) were somewhat compromised for polymerizing activity, but the $3^{\prime}$ to $5^{\prime}$ exo activity was reduced from 6to 50 -fold, depending on the mutation $[116,119]$. Transient expression of the Y577H and Y577H/D581A mutant pol genes complemented the replication of an HSV-1 pol null mutant virus, and viable virus progeny could be isolated when the mutations were introduced into the viral genome [116]. These viruses displayed a mutator phenotype with mutation frequencies that were 300- and 800-fold higher, respectively, than that for the parental wild-type virus [116]. The mutator phenotype of Exo III mutant viruses clearly demonstrates an important role for the intrinsic exo activity of the HSV-1 DNA polymerase in maintaining fidelity of viral DNA replication in culture. However, the inability of other exo-deficient polymerases to support virus replication, particularly the Exo I site mutants with wild-type polymerizing activity, suggests a more complex role for this domain during viral DNA replication.

\subsection{Discrimination between Correct versus Incorrect Nucle-} otide for Incorporation by HSV-1 DNA Polymerase. Presteady-state kinetic analysis can provide a better understanding of the complex interactions between the polymerizing and exo functional domains by determining the individual parameters that control correct and incorrect nucleotide incorporation with undamaged template or a template with a noninformative lesion, such as an AP site. Table 1 summarizes the results of several different pre-steady-state kinetic studies of single nucleotide incorporation by various HSV-1 polymerases - that is, the wild-type and the Exo I site mutant (D368A) pols with or without the UL42 processivity factor. For better comparisons, only the apparent $K_{\mathrm{d}} \mathrm{s}$ for dNTP are shown since true $K_{\mathrm{d}}$ for dNTP was determined in only one study [64]. The rate constants for correct nucleotide incorporation by the wild-type HSV-1 pol in the absence or 
presence of UL42 processivity factor were not significantly different in two different sequence contexts (Table 1 and [64]). This contrasts with the ability of PCNA to increase the rates of polymerization by mammalian pol $\delta$ approximately 3 -fold [39].

For wild-type HSV-1 pol, the rate constant for misincorporation of dATP opposite dA template $(106 / \mathrm{sec})$ was only moderately less than for correct incorporation of $\operatorname{dTTP}(157 / \mathrm{sec})$ into the same P/T (Table 1). Discrimination between the correct and incorrect nucleotide for HSV-1 pol occurs predominantly at the level of ground state binding affinity of dNTP, as indicated by a $>20$-fold decrease in affinity of dATP (incorrect) compared to dTTP (correct) for dA-containing template. Although the processivity factor slowed the rate of incorporation of mismatched dNTP by the wild-type pol approximately 4 -fold, the pol/UL42 complex had an even greater difference in affinity between incorrect and correct dNTP compared to the wild-type pol catalytic subunit. Thus, HSV-1 pol, with or without processivity factor, discriminates between correct versus incorrect dNTP with similar relative efficiencies (Table 1). The relative discrimination values shown in Table 1 (34 and 130) differ somewhat from published values, since the latter used the lower true $K_{\mathrm{d}}(\mathrm{dNTP})$ values to estimate a misincorporation frequency of 1 in 300 for both pol and pol/UL42 [64]. This misincorporation frequency is approximately 10 times higher than that reported for the exo-deficient Klenow fragment of E. coli DNA polymerase I [53], suggesting that HSV-1 pol is one of the least faithful DNA polymerases with intrinsic exo activity [64]. It is interesting to note that a misincorporation frequency of 1 in 300 is similar to the nucleotide variation within the HSV-1 tk locus (an average of 3.3 changes for a gene of $\sim 1,000 \mathrm{bp}$ ) noted among Japanese isolates [114]. Most other studies that have estimated lower HSV-1 mutation frequencies (between $5 \times 10^{-5}$ and $5 \times$ $10^{-4}$ ) have relied on the frequencies for isolating mutations in genes that are scored by function, such as acyclovirresistance [116] or plaque color due to mutation in a lac $\mathrm{Z}$ locus introduced into the viral genome $[120,121]$. Such studies naturally underestimate misincorporation frequency because they fail to score silent mutations that do not alter phenotype.

The D368A mutation renders the polymerase completely deficient in exo function but with a pre-steady-state polymerization rate constant for incorporation of correct nucleotide that is approximately $20 \%$ higher for the mutant catalytic subunit $(199 / \mathrm{sec})$ compared to the wild-type pol on the same $\mathrm{P} / \mathrm{T}$ (Table 1). Although the relative differences in ground state binding affinity for mismatched versus matched nucleotide were similar for the $\mathrm{exo}^{-}$and wild-type pols, the pre-steady-state rate constant for incorporating an incorrect nucleotide by this mutant pol was 23 times lower than that for incorporating a correct one (Table 1). This results in an overall 600-fold reduced efficiency for incorporation of incorrect compared to correct dNTP by the exo ${ }^{-}$pol. Overall, the HSV-1 exo $^{-}$pol misincorporates nucleotides $>5$-times less efficiently than does the wild-type pol using the same $\mathrm{P} / \mathrm{T}$ (Table 1). Thus, the HSV-1 exo- pol misincorporation efficiency differs from that of exo-deficient Klenow enzyme by a factor of only 2 [53]. As discussed in detail in a subsequent section, the lower misincorporation efficiencies observed by the HSV-1 exo- pol, compared to the wildtype pol, may reflect a defect in the ability of the enzyme, or enzyme:incorrect dNTP ternary complex, to transfer the primer terminus between the polymerizing and exo sites.

The specific impact of the UL42 processivity factor on the efficiency with which the exo-deficient pol can discriminate between incorrect and correct nucleotides for incorporation cannot be determined from Table 1. However, the groundstate binding affinity of the antiviral compound, acyclovir (ACV) triphosphate, for the exo- ${ }^{-}$pol/UL42 complex, is roughly the same as the affinity of dGTP for incorporation opposite a $\mathrm{dC}$ templating residue $[78,122]$ (Table 1). By contrast, the rate constant for incorporation of ACV-TP by the $\mathrm{exo}^{-} \mathrm{pol} / \mathrm{UL} 42$ complex is considerably slower than the rate constant for incorporation of matched dNTP by the $\mathrm{exo}^{-}$pol, but similar to that for incorporation of mismatched nucleotide by the exo ${ }^{-}$catalytic subunit (Table 1). Thus, it is likely that the slow rate-limiting step for incorporation of ACV-TP by the exo- pol/UL42 reflects a slow conformational change and/or chemistry step, as suggested for mismatched dNTP incorporation [50].

3.4. Kinetics of Nucleotide Incorporation at AP Sites by HSV1 DNA Polymerase. The kinetic parameters that govern nucleotide incorporation by the HSV-1 pol opposite an AP site on the template differ from those for either correct or incorrect incorporation with undamaged templates. For example, for wild-type pol, there is no significant difference in the rate constant for incorporation $\left(k_{\mathrm{pol}}\right)$ of dATP opposite the matched dT compared to that for incorporation opposite an AP site (Table 1). Pre-steady-state kinetic experiments also revealed that the productive binding of the HSV-1 pol to a $\mathrm{P} / \mathrm{T}$ containing an AP site located 1 nucleotide downstream $(+1)$ from the $\mathrm{P} / \mathrm{T}$ interface (true $K_{\mathrm{d}}(\mathrm{DNA})=42.1 \pm 7.4 \mathrm{nM}$; [79]) was indistinguishable from that for undamaged $\mathrm{P} / \mathrm{T}$ (true $K_{\mathrm{d}}(\mathrm{DNA})=44 \pm 3.0 \mathrm{nM}$; [64]). These results suggest that the enzyme cannot sense the AP site on the template strand ahead of attempts at incorporation. Nevertheless, the ground state binding affinity for dATP opposite the noncoding AP site $\left(1 / K_{\mathrm{d}}\right)$ was reduced approximately 5fold for wild-type pol compared to that for incorporation opposite a matched nucleotide (Table 1).

3.5. Presteady-State Kinetics of Excision by the HSV-1 DNA Polymerase. Under single turnover conditions in which the wild-type pol is bound to $\mathrm{P} / \mathrm{T}$ at equilibrium and excision is initiated by the addition of $\mathrm{MgCl}_{2}$ with high-excess cold DNA trap, the kinetics for excision of a mismatched $\mathrm{P} / \mathrm{T}$, or a P/T containing dA opposite an AP site, approach that for excision of frayed ssDNA ends by the wild-type pol/UL42 holoenzyme (Table 2, $[64,78]$ ). The fast burst rate constant for excision of matched $\mathrm{P} / \mathrm{T}$ by wild-type pol is considerably slower than that for mismatched or A:AP P/Ts (Table 2). In addition, a smaller proportion of matched primer was cleaved, compared to primer opposite a mismatched or AP-containing template. Wild-type pol/UL42 also cleaved 
a smaller proportion of matched ends compared to frayed ones, and with a smaller burst rate constant (Table 2). These results indicate that most of the matched $\mathrm{P} / \mathrm{T}$ is held at equilibrium in the polymerization site with little difference in the relative distribution in the presence $(12.5 \%)$ versus absence $(6 \%)$ of processivity factor. Because the presence of excess unlabeled DNA trap prevents access of labeled P/T to any polymerase that dissociates, the slow burst rate constant for excision, when present, is indicative of the rate by which the primer strand is destabilized and transferred to the exo active site in a single association event $(2.2 / \mathrm{sec}$ for pol and $0.25 / \mathrm{sec}$ for pol/UL42; Table 2). From these data alone, it is difficult to determine whether the differences observed in both fast and slow burst rate constants for cleavage of a $\mathrm{dA} / \mathrm{dT}$ matched $\mathrm{P} / \mathrm{T}$ by pol, compared to those for cleavage of $\mathrm{dG} / \mathrm{dC}$ matched $\mathrm{P} / \mathrm{T}$ by pol/UL42, reflect a greater thermal stability of the $\mathrm{dG} / \mathrm{dC}$ base-pair or a significant slowing of excision rate by UL42. However, in side-by-side comparisons on the same matched P/T, Chaudhuri et al. [64] demonstrated no more than a 2 -fold reduction in fast burst rates for cleavage of matched $\mathrm{P} / \mathrm{T}$ in the presence versus the absence of UL42.

Although HSV-1 pol excises the $3^{\prime}$ nucleotide from mismatched or A:AP P/Ts at rates similar to those for ssDNA (unpublished results, but exemplified by the fast rates of excision of frayed ends by pol/UL42), only a portion of the $\mathrm{P} / \mathrm{Ts}$ occupied by the pol are cleaved at the fast burst rate in a single-turnover (Table 2). Since no slow burst rate was observed for wild-type pol with either $\mathrm{P} / \mathrm{T}$, the results indicate that the remainder of the $\mathrm{P} / \mathrm{Ts}$ were either not bound to the enzyme or dissociated from it at a rate faster than that required to transfer the $3^{\prime}$ primer terminus from the polymerizing to the exo site. In the presence of pol/UL42, not only is a large proportion of frayed primer cleaved with a fast burst rate constant, but the remainder that bound initially at the polymerization site (27\%; Table 2$)$ was transferred to the exo active site for cleavage prior to dissociation. These results suggest that UL42 might increase the overall fidelity of DNA synthesis by increasing the probability that a mismatched P/T will be excised prior to its dissociation from wild-type pol during processive synthesis, when most of the primer would be expected to be located at the polymerizing site.

As previously indicated by steady-state kinetic analysis [122], pre-steady-state kinetic analysis reveals that the excision of ACV-TP opposite the matched $\mathrm{dC}$ template is extremely slow, with a burst rate constant approximately 2000 -fold slower than for the fast burst rate constant for excision of dG on matched template [78] (Table 2). Excision is slowed another 25-fold when dNTP is present. In all cases, the excision rate is slower than the rate of transfer from the pol to the exo site and/or the rate of dissociation from the $\mathrm{P} / \mathrm{T}$ since no slower burst rate was observed. The association of next correct dNTP has been reported to lock the polymerase into a dead-end complex with ACVTP [122]. However, the comparatively small difference in excision burst rate constants in the presence versus absence of dNTP following ACV incorporation may suggest that the dNTP stabilizes a replicating $\mathrm{P} / \mathrm{T}$ within the polymerizing site, thereby reducing its rate of transfer from the pol to exo site $[57,78]$. Taken together, these results suggest the importance of the HSV-1 pol to possess a dynamic ability to switch the $\mathrm{P} / \mathrm{T}$ between the polymerizing and exo sites for its ability to function properly, and a role for UL42 in preventing dissociation of pol from a mismatched primer terminus during active DNA extension.

\subsection{Mismatch Extension by HSV-1 Pol during Processive} Synthesis. Early steady-state experiments were used to determine the ability of the HSV-1 pol to extend mismatches [123]. Despite potent exo activity, the wild-type HSV-1 pol was observed to extend mismatches at high concentrations of next correct single nucleotide. However, the efficiency $\left(V_{\max } / K_{\mathrm{m}}\right)$ for wild-type pol extension of mismatches with next correct nucleotide was considerably lower than for the exo $^{-}$pol $[75,123]$. This was due in large part to cleavage of the mismatched primer terminus by the exo activity of the wild-type pol, resulting in an incorrectly matched $\mathrm{P} / \mathrm{T}$ for extension with the tested nucleotide. Indeed, when the template nucleotide located at position -1 with respect to the mismatched primer terminus was complementary to the incoming nucleotide, efficiency for extending the "mismatched" P/T was virtually the same as for matched $[75,119]$. Because dissociation would effectively reduce the $V_{\max }$, these results demonstrate the effective ability of the wild-type HSV-1 pol to switch the primer to the exo site, cleave the mismatch, switch it back to the polymerizing site, and incorporate new nucleotide, all without dissociating. It also suggests that with this kinetic partitioning, there is little cost to extension efficiency when proof-reading by the HSV-1 polymerase is required. Nevertheless, steady-state experiments do not provide an accurate measure of the ability of a polymerase to extend uncorrected mismatches.

Running-start single-turnover experiments have been used to gain a better understanding of the kinetic barrier for HSV-1 pol to extend mismatches and how the polymerase responds to misincorporation during active polymerization [75]. The data in [75] have been adapted and included in Figure 1 for comparative purposes. In these experiments, the terminus of a $5^{\prime}$ end-labeled primer was located 3 nucleotides upstream $(-3)$ of a target site that forced misincorporation due to the absence of matched nucleotide in the pool (Figure 1(a)). Critical to these experiments was (1) a saturating or close to saturating concentration of all other nucleotides, (2) equilibrium binding of the polymerase to the $\mathrm{P} / \mathrm{T}$ prior to initiation (in the presence of EDTA), and (3) initiation of reactions with $\mathrm{MgCl}_{2}$ and excess DNA to trap any polymerase molecules that dissociate from the $\mathrm{P} / \mathrm{T}$ following initiation [75]. Because active polymerization would occur for several nucleotides, the $\mathrm{P} / \mathrm{T}$ would be expected to be firmly bound to the polymerase active site for several cycles of processive correct nucleotide incorporations prior to a forced misincorporation event. Surprisingly, three-fourths of the P/T productively engaged by the wild-type pol misincorporated nucleotide at the target position, and two-thirds of those were extended by at least one additional nucleotide prior to dissociation (accounting for $48 \%$ of total $\mathrm{P} / \mathrm{T}$ productively bound by 
the pol, see Figure 1(b)). The presence of a strong pause site [75] suggests that the wild-type pol switches the primer end to the exo site, cleaves the mismatch to form a matched $\mathrm{P} / \mathrm{T}$, then rapidly switches back to the pol site for another forced misincorporation event. Repeated cycles of excision and incorporation (idling) then ensue in a single association of the pol catalytic subunit with $\mathrm{P} / \mathrm{T}$, until the mismatch is successfully extended (Figure 1(b)). These results indicate that the rate of transfer of the mismatched primer terminus between the polymerizing and exo sites (one or more times) is greater than the rate of dissociation of the wild-type pol from the $\mathrm{P} / \mathrm{T}$ during forced misincorporation.

The exo ${ }^{-}$HSV-1 pol also misincorporated and extended mismatches, but the kinetics for misincorporation were markedly slower compared with wild-type pol, with only half of the productively engaged $\mathrm{exo}^{-}$pol misincorporating within $2 \mathrm{sec}$ (Figure 1(c)). The latter results are in excellent agreement with the less efficient ability of the exocompared to the wild-type pol, in incorporating an incorrect nucleotide in standing start experiments (Table 1). However, a similar proportion of available mismatched $\mathrm{P} / \mathrm{T}$ was extended by the exo ${ }^{-}$pol, compared with the wild-type pol, albeit at a slower rate. The near linear kinetics for mismatch extension by the exo ${ }^{-}$pol are not the result of multiple turnovers of enzyme with $\mathrm{P} / \mathrm{T}$ because of the presence of DNA trap. Instead, the absence of a burst likely indicates that the rate-limiting step is the slow rate of primer switching $(\sim 0.24 / \mathrm{sec}[75])$ from the polymerizing to the exo site and back when the mismatch cannot be cleaved.

The impact of the UL42 processivity factor in preventing mismatch extension is clearly observed in these running start experiments. Not only do fewer mismatched $\mathrm{P} / \mathrm{T}$ accumulate in the presence $(26 \%)$ versus absence $(76 \%)$ of UL42, but only $5.6 \%$ of all $\mathrm{P} / \mathrm{T}$ ( $21 \%$ of those that misincorporated) are extended one nucleotide beyond the mismatch and none were extended further (Figure 1(d); [75]). Because the rates of incorporation of incorrect nucleotide and excision of mismatches or frayed ends (Tables 1 and 2, resp.) do not differ substantially for wild-type HSV-1 pol in the presence or absence of processivity factor, the results suggest that UL42 increases the efficiency and/or rates by which the mismatched/frayed primer terminus is transferred between the polymerizing and exo sites in a single association event during active replication.

3.7. Failure of the HSV-1 DNA Polymerase to Bypass AP Lesions during Active Replication. Similar running-start single-turnover experiments have been performed on $\mathrm{P} / \mathrm{Ts}$ in which the target site on the template was an AP site, located $4 \mathrm{nt}$ downstream of the primer terminus (Figure 1(f)). The data have been adapted from a previously published report [79] to permit side-by-side comparisons with mismatch extension data [75]. The wild-type HSV-1 pol extended the primer to the AP target site with more rapid burst kinetics than it did to a misincorporation target (compare Figures $1(\mathrm{~g})$ and $1(\mathrm{~b})$ ). However, compared to mismatches, AP sites posed a greater kinetic barrier to extension by the wild-type HSV-1 pol, since no lesion bypass was detected
(Figure 1(g); [79]). With such a high kinetic barrier, the rate of dissociation of the pol from the damaged $\mathrm{P} / \mathrm{T}$ exceeded that required for extension, resulting in a smaller percentage $(30 \%)$ of primer extended to the AP target site (Figure $1(\mathrm{~g})$ ) compared to that which resulted from misincorporation (76\%; Figure 1(b)).

The absence of exo activity prevents excision of the residue that is incorporated opposite an AP site and, as observed following misincorporation, this slows the transfer of primer between the exo and polymerizing sites. Although the $\mathrm{exo}^{-}$pol was able to bypass AP lesions, bypass synthesis was extremely inefficient (Figure $1(\mathrm{~h})$ ). These results are in agreement with the requirement for exo-deficiency in order for the HSV-1 pol to incorporate nucleotide opposite a cisplatin cross-link [88]. It was also shown in those studies that neither the wild-type nor $\mathrm{exo}^{-}$pol, with or without UL42 processivity subunit, could completely bypass the cisplatin lesion. However, UL42 did increase the ability of HSV-1 exo $^{-}$pol to incorporate nucleotide opposite the cisplatin lesion [88]. No studies to date have examined the ability of UL42 to permit AP lesion bypass synthesis.

AP sites have been shown to be present in HSV-1 replicating and virion DNA at a frequency of 2.8-5.9/genome equivalent [79]. Given that wild-type pol is unable to bypass these lesions, there must be other mechanisms to permit synthesis through or around AP lesions, such as recombination or repair. The newly discovered AP and $5^{\prime}-$ deoxyribose phosphate lyase activities of the HSV-1 pol, both of which are involved in base excision repair, might perform such a task to repair AP lesions [124]. It is also possible that other viral DNA replication components would permit lesion bypass.

\subsection{Importance of Kinetic Partitioning between the Polymeriz-} ing and exo Sites for Fidelity. The kinetic barrier to extending a mismatched $\mathrm{P} / \mathrm{T}$ prevents most misincorporation events from becoming fixed mutations. The exo activity of the HSV1 pol reinforces the kinetic barrier by permitting excision of the mismatched primer terminus when the polymerase "stalls". In reality, the polymerase does not truly stall when it encounters a kinetic barrier, but rather engages in idling at that site through successive rounds of incorporation and excision, even in the absence of the UL42 processivity factor. The idling activity is made possible by the ability of the polymerase to dynamically switch the $\mathrm{P} / \mathrm{T}$ from the polymerizing site to the exo site and back. Pre-steady-state kinetic analysis has demonstrated that UL42 increases the processivity of the HSV- 1 pol from $\sim 1700$ to $>5,000$ per association event [64]. UL42 also increases the efficiency of excision of mismatches formed during processive DNA synthesis by increasing the rate and/or efficiency of transfer of the mismatched primer between the polymerizing and exo active sites. This makes UL42 an unusual fidelity factor because it affects neither the rates of polymerization nor the rates of excision [64]. Moreover, UL42 does not promote mismatch extension or lesion bypass, distinguishing it from the functions of the processivity factors of polymerases in the 
same family, such as T4 DNA polymerase and mammalian pol $\delta[90,91,94]$.

Mounting evidence suggests that altering the ability of the HSV-1 pol to switch between the exo and pol active sites will have an impact on fidelity. It is interesting to note that mutations in UL42 that either increase or decrease affinity for DNA result in decreased replication fidelity and reduced numbers of viable virus progeny $[120,121]$. Although classical measures of this idling activity depend on the presence of a functional exo activity [85], the runningstart single-turnover experiments described in Figure 1 demonstrate the ability of the HSV-1 polymerase to switch the primer terminus between the exo and pol sites even in the absence of exo catalytic activity. However, the increased affinity of the exo site for mismatched primer (ssDNA), and the corresponding decreased affinity of mismatched DNA for the polymerizing site, renders the catalytically inactivated Exo I site mutant pol (D368A) less efficient in switching behavior and in extending mismatched primers $[75,123]$. The fact that the Exo I mutant pol is also slower in its ability to incorporate incorrect dNTP than the wild-type pol suggests that binding of an incorrectly matched dNTP to the HSV-1 pol may destablize the association of the primer terminus with the polymerizing active site. UL42 slows the rate of switching of the $\mathrm{exo}^{-}$pol on mismatched termini during processive synthesis even more (Figure 1(e); and [75]). If the rate of switching is slower than that for dissociation of the polymerase from the $\mathrm{P} / \mathrm{T}$, then extension would be disfavored, which could explain why no viable progeny have been isolated with this particular mutation [117].

Mutations outside the exo domain may also impact $\mathrm{P} / \mathrm{T}$ switching by the HSV-1 pol. Kinetic analysis of HSV1 pol containing a finger domain mutation (L774F) showed significant stalling during normal elongation and a decreased efficiency for extending mismatches $[125,126]$. When introduced into the pol gene of the virus, this mutation increased fidelity of DNA synthesis compared to that of the parental virus, regardless of the presence or absence of an Exo III site mutation $[125,126]$. These properties are consistent with enhanced idling-turnover ability and increased primer switching compared to the wild-type pol. For T4 DNA polymerase, mutations that increase the switching rate have also been shown to possess antimutator activity [41], consistent with the importance of the ability of the pol to efficiently transfer the primer end between the polymerizing and exo active sites to maintain fidelity. Since the T4 switch mutations do not map to the same domain as the HSV1 L774F mutation, additional studies will be required to ascertain the mechanism by which the HSV-1 finger domain mutant enhances replication fidelity.

3.9. Kinetic Partitioning and Virus Viability. The ability of the HSV-1 DNA polymerase to engage in dynamic switching of $\mathrm{P} / \mathrm{T}$ between the pol and exo sites when kinetic barriers to extension are encountered is likely to be essential to the viability of virus. It is interesting to note that part of the effectiveness of the chain-terminator, acyclovir, now appears to be its influence on the ability of the HSV-1 pol to switch the primer terminus between the polymerizing and exo sites. As suggested by Hanes et al. [78], the addition of dNTP to an HSV-1 pol that has incorporated ACV may favor retention of the ACV-containing $\mathrm{P} / \mathrm{T}$ at the pol site, making $\mathrm{ACV}$ less likely to be removed by the exo activity.

We propose that compounds that specifically target the HSV-1 pol exo activity for inactivation, or that significantly inhibit the ability of replicating viral DNA to be transferred between the polymerizing and exo sites, would be effective antiviral agents. By holding the primer terminus in the exo site, extension by the polymerase would be slowed and could lead to chain termination and replication failure. Holding the primer in the polymerase active site would be expected to decrease the ability of the polymerase to excise mismatches that are frequently formed by the polymerase and to increase the probability for mismatch extension. This would lead to the accumulation of a lethal number of mutations during replication. Due to the conserved nature of the polymerase among the herpesvirus family members [99], it should be possible to target other herpesvirus polymerases in the same way, particularly those for which no effective nontoxic inhibitor has been identified to date.

\section{Acknowledgments}

This work was supported in part by parent Grant GM 034930 and American Reinvestment and Recovery Act Supplement GM 034930-04S1 from the National Institutes of Health (D.S.P.). During part of this work, Y. Zhu was supported by a training Grant from the National Cancer Institute (CA 09338). Core services were provided by the Ohio State University Comprehensive Cancer Center and the Department of Molecular Virology, Immunology, and Medical Genetics.

\section{References}

[1] J. P. Wittschieben, S. C. Reshmi, S. M. Gollin, and R. D. Wood, "Loss of DNA polymerase $\zeta$ causes chromosomal instability in mammalian cells," Cancer Research, vol. 66, no. 1, pp. 134-142, 2006.

[2] R. N. Venkatesan, P. M. Treuting, E. D. Fuller et al., "Mutation at the polymerase active site of mouse DNA polymerase $\delta$ increases genomic instability and accelerates tumorigenesis," Molecular and Cellular Biology, vol. 27, no. 21, pp. 7669-7682, 2007.

[3] A. Trifunovic, A. Wredenberg, M. Falkenberg et al., "Premature ageing in mice expressing defective mitochondrial DNA polymerase," Nature, vol. 429, no. 6990, pp. 417-423, 2004.

[4] Q. Lin, A. B. Clark, S. D. McCulloch et al., "Increased susceptibility to UV-induced skin carcinogenesis in polymerase

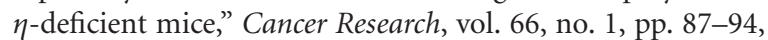
2006.

[5] R. E. Goldsby, N. A. Lawrence, L. E. Hays et al., "Defective DNA polymerase- $\delta$ proofreading causes cancer susceptibility in mice," Nature Medicine, vol. 7, no. 6, pp. 638-639, 2001.

[6] R. E. Goldsby, L. E. Hays, X. Chen et al., "High incidence of epithelial cancers in mice deficient for DNA polymerase $\delta$ proofreading," Proceedings of the National Academy of 
Sciences of the United States of America, vol. 99, no. 24, pp. 15560-15565, 2002.

[7] C. A. Dumstorf, A. B. Clark, Q. Lin et al., "Participation of mouse DNA polymerase $\iota$ in strand-biased mutagenic bypass of UV photoproducts and suppression of skin cancer," Proceedings of the National Academy of Sciences of the United States of America, vol. 103, no. 48, pp. 18083-18088, 2006.

[8] A. B. Robertson, A. Klungland, T. Rognes, and I. Leiros, "DNA repair in mammalian cells: base excision repair: the long and short of it," Cellular and Molecular Life Sciences, vol. 66, no. 6, pp. 981-993, 2009.

[9] T. A. Kunkel and D. A. Erie, "DNA mismatch repair," Annual Review of Biochemistry, vol. 74, pp. 681-710, 2005.

[10] J. Jiricny, "The multifaceted mismatch-repair system," Nature Reviews Molecular Cell Biology, vol. 7, no. 5, pp. 335-346, 2006.

[11] P. C. Hanawalt, "Paradigms for the three Rs: DNA replication, recombination, and repair," Molecular Cell, vol. 28, no. 5, pp. 702-707, 2007.

[12] A. M. Woodside and F. P. Guengerich, "Misincorporation and stalling at $O^{6}$-methylguanine and $O^{6}$-benzylguanine: evidence for inactive polymerase complexes," Biochemistry, vol. 41, no. 3, pp. 1039-1050, 2002.

[13] L. G. Lowe and F. P. Guengerich, "Steady-state and presteady-state kinetic analysis of dNTP insertion opposite 8oxo-7,8-dihydroguanine by Escherichia coli polymerases I exo $^{-}$and II exo ${ }^{-}, "$ Biochemistry, vol. 35 , no. 30 , pp. 9840 9849, 1996.

[14] N. Tanguy Le Gac, E. Delagoutte, M. Germain, and G. Villani, 'Inactivation of the 3'-5' exonuclease of the replicative T4 DNA polymerase allows translesion DNA synthesis at an abasic site," Journal of Molecular Biology, vol. 336, no. 5, pp. 1023-1034, 2004.

[15] R. D. Kuchta, P. Benkovic, and S. J. Benkovic, "Kinetic mechanism whereby DNA polymerase I (Klenow) replicates DNA with high fidelity," Biochemistry, vol. 27, no. 18, pp. 6716-6725, 1988.

[16] M. F. Goodman and D. K. Fygenson, "DNA polymerase fidelity: from genetics toward a biochemical understanding," Genetics, vol. 148, no. 4, pp. 1475-1482, 1998.

[17] H. Echols and M. F. Goodman, "Fidelity mechanisms in DNA replication," Annual Review of Biochemistry, vol. 60, pp. 477511, 1991.

[18] P. Stelter and H. D. Ulrich, "Control of spontaneous and damage-induced mutagenesis by SUMO and ubiquitin conjugation," Nature, vol. 425, no. 6954, pp. 188-191, 2003.

[19] S. Prakash and L. Prakash, "Translesion DNA synthesis in eukaryotes: a one- or two-polymerase affair," Genes and Development, vol. 16, no. 15, pp. 1872-1883, 2002.

[20] S. D. McCulloch and T. A. Kunkel, "The fidelity of DNA synthesis by eukaryotic replicative and translesion synthesis polymerases," Cell Research, vol. 18, no. 1, pp. 148-161, 2008.

[21] C. Hoege, B. Pfander, G.-L. Moldovan, G. Pyrowolakis, and S. Jentsch, "RAD6-dependent DNA repair is linked to modification of PCNA by ubiquitin and SUMO," Nature, vol. 419, no. 6903, pp. 135-141, 2002.

[22] L. Haracska, I. Unk, R. E. Johnson et al., "Stimulation of DNA synthesis activity of human DNA polymerase $\kappa$ by PCNA," Molecular and Cellular Biology, vol. 22, no. 3, pp. 784-791, 2002.
[23] L. Haracska, I. Unk, R. E. Johnson et al., "Roles of yeast DNA polymerases $\delta$ and $\zeta$ of Rev 1 in the bypass of abasic sites," Genes and Development, vol. 15, no. 8, pp. 945-954, 2001.

[24] L. Haracska, S. Prakash, and L. Prakash, "Yeast DNA polymerase $\zeta$ is an efficient extender of primer ends opposite from 7,8-dihydro-8-oxoguanine and $O^{6}$-methylguanine," Molecular and Cellular Biology, vol. 23, no. 4, pp. 1453-1459, 2003.

[25] L. Haracska, L. Prakash, and S. Prakash, "Role of human DNA polymerase $\kappa$ as an extender in translesion synthesis," Proceedings of the National Academy of Sciences of the United States of America, vol. 99, no. 25, pp. 16000-16005, 2002.

[26] L. Haracska, C. M. Kondratick, I. Unk, S. Prakash, and L. Prakash, "Interaction with PCNA is essential for yeast DNA polymerase $\eta$ function," Molecular Cell, vol. 8, no. 2, pp. 407415, 2001.

[27] L. Haracska, R. E. Johnson, I. Unk et al., "Targeting of human DNA polymerase $\iota$ to the replication machinery via interaction with PCNA," Proceedings of the National Academy of Sciences of the United States of America, vol. 98, no. 25, pp. 14256-14261, 2001.

[28] M. F. Goodman, "Error-prone repair DNA polymerases in prokaryotes and eukaryotes," Annual Review of Biochemistry, vol. 71, pp. 17-50, 2002.

[29] E. C. Friedberg, R. Wagner, and M. Radman, "Specialized DNA polymerases, cellular survival, and the genesis of mutations," Science, vol. 296, no. 5573, pp. 1627-1630, 2002.

[30] L. J. Reha-Krantz, "Regulation of DNA polymerase exonucleolytic proofreading activity: studies of bacteriophage T4 'antimutator' DNA polymerases," Genetics, vol. 148, no. 4, pp. 1551-1557, 1998.

[31] A. A. Johnson and K. A. Johnson, "Exonuclease proofreading by human mitochondrial DNA polymerase," Journal of Biological Chemistry, vol. 276, no. 41, pp. 38097-38107, 2001.

[32] F. Foury and S. Vanderstraeten, "Yeast mitochondrial DNA mutators with deficient proofreading exonucleolytic activity," EMBO Journal, vol. 11, no. 7, pp. 2717-2726, 1992.

[33] M. J. Donlin, S. S. Patel, and K. A. Johnson, "Kinetic partitioning between the exonuclease and polymerase sites in DNA error correction," Biochemistry, vol. 30, pp. 538-546, 1991.

[34] T. L. Capson, J. A. Peliska, B. F. Kaboord et al., "Kinetic characterization of the polymerase and exonuclease activities of the gene 43 protein of bacteriophage T4," Biochemistry, vol. 31, no. 45, pp. 10984-10994, 1992.

[35] A. J. Berdis, "Dynamics of translesion DNA synthesis catalyzed by the bacteriophage T4 exonuclease-deficient DNA polymerase," Biochemistry, vol. 40, no. 24, pp. 7180-7191, 2001.

[36] A. Bebenek, G. T. Carver, H. K. Dressman et al., "Dissecting the fidelity of bacteriophage RB69 DNA polymerase: sitespecific modulation of fidelity by polymerase accessory proteins," Genetics, vol. 162, no. 3, pp. 1002-1018, 2002.

[37] M. Hogg, S. S. Wallace, and S. Doublié, "Crystallographic snapshots of a replicative DNA polymerase encountering an abasic site," EMBO Journal, vol. 23, no. 7, pp. 1483-1493, 2004.

[38] R. D. Kuchta, V. Mizrahi, P. A. Benkovic, K. A. Johnson, and S. J. Benkovic, "Kinetic mechanism of DNA polymerase I (Klenow)," Biochemistry, vol. 26, no. 25, pp. 8410-8417, 1987.

[39] H. J. Einolf and F. P. Guengerich, "Kinetic analysis of nucleotide incorporation by mammalian DNA polymerase 
\&," Journal of Biological Chemistry, vol. 275, no. 21, pp. 16316-16322, 2000.

[40] M. Hogg, W. Cooper, L. Reha-Krantz, and S. S. Wallace, "Kinetics of error generation in homologous B-family DNA polymerases," Nucleic Acids Research, vol. 34, no. 9, pp. 25282535, 2006.

[41] S. A. Stocki, R. L. Nonay, and L. J. Reha-Krantz, "Dynamics of bacteriophage T4 DNA polymerase function: identification of amino acid residues that affect switching between polymerase and 3' $\rightarrow$ 5' exonuclease activities," Journal of Molecular Biology, vol. 254, no. 1, pp. 15-28, 1995.

[42] L. J. Reha-Krantz and M. J. Bessman, "Studies on the biochemical basis of mutation VI. Selection and characterization of a new bacteriophage T4 mutator DNA polymerase," Journal of Molecular Biology, vol. 145, no. 4, pp. 677-695, 1981.

[43] N. Muzyczka, R. L. Poland, and M. J. Bessman, "Studies on the biochemical basis of spontaneous mutation. I. A comparison of the deoxyribonucleic acid polymerases of mutator, antimutator, and wild type strains of bacteriophage T4," Journal of Biological Chemistry, vol. 247, no. 22, pp. 7116-7122, 1972.

[44] M. S. Hershfield, "On the role of deoxyribonucleic acid polymerase in determining mutation rates. Characterization of the defect in the T4 deoxyribonucleic acid polymerase caused by the ts L88 mutation," Journal of Biological Chemistry, vol. 248, no. 4, pp. 1417-1423, 1973.

[45] A. R. Fersht, "Fidelity of replication of phage $\phi$ X174 DNA by DNA polymerase III holoenzyme: Spontaneous mutation by misincorporation," Proceedings of the National Academy of Sciences of the United States of America, vol. 76, no. 10, pp. 4946-4950, 1979.

[46] H. Mitsuya, R. F. Jarrett, and M. Matsukura, "Longterm inhibition of human T-lymphotropic virus type III/lymphadenopathy-associated virus (human immunodeficiency virus) DNA synthesis and RNA expression in T cells protected by 2',3'-dideoxynucleosides in vitro," Proceedings of the National Academy of Sciences of the United States of America, vol. 84, no. 7, pp. 2033-2037, 1987.

[47] P. A. Furman, J. A. Fyfe, M. H. St. Clair et al., "Phosphorylation of 3'-azido-3'-deoxythymidine and selective interaction of the 5'-triphosphate with human immunodeficiency virus reverse transcriptase," Proceedings of the National Academy of Sciences of the United States of America, vol. 83, no. 21, pp. 8333-8337, 1986.

[48] G. B. Elion, "The biochemistry and mechanism of action of acyclovir," Journal of Antimicrobial Chemotherapy, vol. 12, pp. 9-17, 1983.

[49] I. Wong, "An induced-fit kinetic mechanism for DNA replication fidelity: direct measurement by single-turnover kinetics," Biochemistry, vol. 30, no. 2, pp. 526-537, 1991.

[50] Y.-C. Tsai and K. A. Johnson, "A new paradigm for DNA polymerase specificity," Biochemistry, vol. 45 , no. 32, pp. 9675-9687, 2006.

[51] T. A. Kunkel and K. Bebenek, "DNA replication fidelity," Annual Review of Biochemistry, vol. 69, pp. 497-529, 2000.

[52] W. M. Kati, K. A. Johnson, L. F. Jerva, and K. S. Anderson, "Mechanism and fidelity of HIV reverse transcriptase," Journal of Biological Chemistry, vol. 267, no. 36, pp. 2598825997, 1992.

[53] J. G. Bertram, K. Oertell, J. Petruska, and M. F. Goodman, "DNA polymerase fidelity: comparing direct competition of right and wrong dNTP substrates with steady state and presteady state kinetics," Biochemistry, vol. 49, no. 1, pp. 20-28, 2010.

[54] S. Doublié, S. Tabor, A. M. Long, C. C. Richardson, and T. Ellenberger, "Crystal structure of a bacteriophage T7 DNA replication complex at $2.2 \AA$ resolution,” Nature, vol. 391, no. 6664, pp. 251-258, 1998.

[55] Y.-S. Lee, W. D. Kennedy, and Y. W. Yin, "Structural insight into processive human mitochondrial DNA synthesis and disease-related polymerase mutations," Cell, vol. 139, no. 2, pp. 312-324, 2009.

[56] M. C. Franklin, J. Wang, and T. A. Steitz, "Structure of the replicating complex of a pol $\alpha$ family DNA polymerase," Cell, vol. 105, no. 5, pp. 657-667, 2001.

[57] S. Liu, J. D. Knafels, J. S. Chang et al., "Crystal structure of the herpes simplex virus 1 DNA polymerase," Journal of Biological Chemistry, vol. 281, no. 26, pp. 18193-18200, 2006.

[58] M. K. Swan, R. E. Johnson, L. Prakash, S. Prakash, and A. K. Aggarwal, "Structural basis of high-fidelity DNA synthesis by yeast DNA polymerase $\delta$," Nature Structural and Molecular Biology, vol. 16, no. 9, pp. 979-986, 2009.

[59] S. Moran, R. X.-F. Ren, and E. T. Kool, "A thymidine triphosphate shape analog lacking Watson-Crick pairing ability is replicated with high sequence selectivity," Proceedings of the National Academy of Sciences of the United States of America, vol. 94, no. 20, pp. 10506-10511, 1997.

[60] M. F. Goodman, "Hydrogen bonding revisited: geometric selection as a principal determinant of DNA replication fidelity," Proceedings of the National Academy of Sciences of the United States of America, vol. 94, no. 20, pp. 10493-10495, 1997.

[61] L. S. Beese, V. Derbyshire, and T. A. Steitz, "Structure of DNA polymerase I Klenow fragment bound to duplex DNA," Science, vol. 260, no. 5106, pp. 352-355, 1993.

[62] S. S. Patel, "Pre-steady-state kinetic analysis of processive DNA replication including complete characterization of an exonuclease-deficient mutant," Biochemistry, vol. 30, no. 2, pp. 511-525, 1991.

[63] A. A. Johnson and K. A. Johnson, "Fidelity of nucleotide incorporation by human mitochondrial DNA polymerase," Journal of Biological Chemistry, vol. 276, no. 41, pp. 3809038096, 2001.

[64] M. Chaudhuri, L. Song, and D. S. Parris, "The herpes simplex virus type 1 DNA polymerase processivity factor increases fidelity without altering pre-steady-state rate constants for polymerization or excision," Journal of Biological Chemistry, vol. 278, no. 11, pp. 8996-9004, 2003.

[65] Y.-C. Tsai and K. A. Johnson, "A new paradigm for DNA polymerase specificity," Biochemistry, vol. 45, no. 32, pp. 9675-9687, 2006.

[66] B.-L. Zhou, J. D. Pata, and T. A. Steitz, "Crystal structure of a DinB lesion bypass DNA polymerase catalytic fragment reveals a classic polymerase catalytic domain," Molecular Cell, vol. 8, no. 2, pp. 427-437, 2001.

[67] W. Yang, "Portraits of a Y-family DNA polymerase," FEBS Letters, vol. 579, no. 4, pp. 868-872, 2005.

[68] J. Trincao, R. E. Johnson, C. R. Escalante, S. Prakash, L. Prakash, and A. K. Aggarwal, "Structure of the catalytic core of $S$. cerevisiae DNA polymerase $\eta$ : implications for translesion DNA synthesis," Molecular Cell, vol. 8, no. 2, pp. 417-426, 2001.

[69] H. Ling, F. Boudsocq, R. Woodgate, and W. Yang, "Crystal structure of a Y-family DNA polymerase in action: a 
mechanism for error-prone and lesion-bypass replication," Cell, vol. 107, no. 1, pp. 91-102, 2001.

[70] T. A. Kunkel, L. A. Loeb, and M. F. Goodman, "On the fidelity of DNA replication. The accuracy of T4 DNA polymerases in copying $\phi \mathrm{X} 174$ DNA in vitro," Journal of Biological Chemistry, vol. 259, no. 3, pp. 1539-1545, 1984.

[71] L. C. Kroutil, K. Register, K. Bebenek, and T. A. Kunkel, "Exonucleolytic proofreading during replication of repetitive DNA," Biochemistry, vol. 35, no. 3, pp. 1046-1053, 1996.

[72] L. C. Kroutil, M. West Frey, B. F. Kaboord, T. A. Kunkel, and S. J. Benkovic, "Effect of accessory proteins on T4 DNA polymerase replication fidelity," Journal of Molecular Biology, vol. 278, no. 1, pp. 135-146, 1998.

[73] M. W. Frey, N. G. Nossal, T. L. Capson, and S. J. Benkovic, "Construction and characterization of a bacteriophage T4 DNA polymerase deficient in 3' $\rightarrow$ 5' exonuclease activity," Proceedings of the National Academy of Sciences of the United States of America, vol. 90, no. 7, pp. 2579-2583, 1993.

[74] L. B. Bloom, X. Chen, D. K. Fygenson, J. Turner, M. O'Donnell, and M. F. Goodman, "Fidelity of Escherichia coli DNA polymerase III holoenzyme: the effects of $\beta, \gamma$ complex processivity proteins and $\varepsilon$ proofreading exonuclease on nucleotide misincorporation efficiencies," Journal of Biological Chemistry, vol. 272, no. 44, pp. 27919-27930, 1997.

[75] L. Song, M. Chaudhuri, C. W. Knopf, and D. S. Parris, "Contribution of the 3'- to 5'-exonuclease activity of herpes simplex virus type 1 DNA polymerase to the fidelity of DNA synthesis," Journal of Biological Chemistry, vol. 279, no. 18, pp. 18535-18543, 2004.

[76] M. J. Longley, D. Nguyen, T. A. Kunkel, and W. C. Copeland, "The fidelity of human DNA polymerase $\mathrm{g}$ with and without exonucleolytic proofreading and the p55 accessory subunit," Journal of Biological Chemistry, vol. 276, no. 42, pp. 3855538562, 2001.

[77] C. M. Joyce, "How DNA travels between the separate polymerase and 3'-5'-exonuclease sites of DNA polymerase I (Klenow fragment)," Journal of Biological Chemistry, vol. 264, no. 18, pp. 10858-10866, 1989.

[78] J. W. Hanes, Y. Zhu, D. S. Parris, and K. A. Johnson, "Enzymatic therapeutic index of acyclovir: viral versus human polymerase $\gamma$ specificity," Journal of Biological Chemistry, vol. 282, no. 34, pp. 25159-25167, 2007.

[79] Y. Zhu, L. Song, J. Stroud, and D. S. Parris, "Mechanisms by which herpes simplex virus DNA polymerase limits translesion synthesis through abasic sites," DNA Repair, vol. 7, no. 1, pp. 95-107, 2008.

[80] L. Song, The role of the associated 3' to 5' exonuclease activity and processivity factor (UL42) of herpes simplex virus type 1 DNA polymerase on the fidelity of DNA replication, Ph.D. dissertation, The Ohio State University, Columbus, Ohio, USA, 2004.

[81] Y. Shamoo and T. A. Steitz, "Building a replisome from interacting pieces: Sliding clamp complexed to a peptide from DNA polymerase and a polymerase editing complex," Cell, vol. 99, no. 2, pp. 155-166, 1999.

[82] J. Wang, A. K. M. A. Sattar, C. C. Wang, J. D. Karam, W. H. Konigsberg, and T. A. Steitz, "Crystal structure of a pol $\alpha$ family replication DNA polymerase from bacteriophage RB69," Cell, vol. 89, no. 7, pp. 1087-1099, 1997.

[83] M. Hogg, P. Aller, W. Konigsberg, S. S. Wallace, and S. Doublié, "Structural and biochemical investigation of the role in proofreading of a $\beta$ hairpin loop found in the exonuclease domain of a replicative DNA polymerase of the B family," Journal of Biological Chemistry, vol. 282, no. 2, pp. 14321444, 2007.

[84] E. Fidalgo da silva and L. J. Reha-Krantz, "DNA polymerase proofreading: active site switching catalyzed by the bacteriophage T4 DNA polymerase," Nucleic Acids Research, vol. 35, no. 16, pp. 5452-5463, 2007.

[85] Y. Zhu, K. S. Trego, L. Song, and D. S. Parris, “3' to 5 ' exonuclease activity of herpes simplex virus type 1 DNA polymerase modulates its strand displacement activity," Journal of Virology, vol. 77, no. 18, pp. 10147-10153, 2003.

[86] Y. H. Jin, R. Obert, P. M. J. Burgers, T. A. Kunkel, M. A. Resnick, and D. A. Gordenin, “The 3' $\rightarrow$ 5' exonuclease of DNA polymerase $\delta$ can substitute for the 5 ' flap endonuclease $\operatorname{Rad} 27 / F e n 1$ in processing Okazaki fragments and preventing genome instability," Proceedings of the National Academy of Sciences of the United States of America, vol. 98, no. 9, pp. 5122-5127, 2001.

[87] Y. H. Jin, R. Ayyagari, M. A. Resnick, D. A. Gordeni, and P. M. J. Burgers, "Okazaki fragment maturation in yeast: II. Cooperation between the polymerase and 3'-5'-exonuclease activities of Pol $\delta$ in the creation of a ligatable nick," Journal of Biological Chemistry, vol. 278, no. 3, pp. 1626-1633, 2003.

[88] M. E. Arana, L. Song, N. T. Le Gac, D. S. Parris, G. Villani, and P. E. Boehmer, "On the role of proofreading exonuclease in bypass of a $1,2 \mathrm{~d}(\mathrm{GpG})$ cisplatin adduct by the herpes simplex virus-1 DNA polymerase," DNA Repair, vol. 3, no. 6, pp. 659669, 2004.

[89] V. Khare and K. A. Eckert, 'The proofreading 3' $\rightarrow$ 5' exonuclease activity of DNA polymerases: a kinetic barrier to translesion DNA synthesis," Mutation Research, vol. 510, no. 1-2, pp. 45-54, 2002.

[90] D. J. Mozzherin, S. Shibutani, C.-K. Tan, K. M. Downey, and P. A. Fisher, "Proliferating cell nuclear antigen promotes DNA synthesis past template lesions by mammalian DNA polymerase $\delta$," Proceedings of the National Academy of Sciences of the United States of America, vol. 94, no. 12, pp. 6126-6131, 1997.

[91] G. Blanca, E. Delagoutte, N. Tanguy Le Gac, N. P. Johnson, G. Baldacci, and G. Villani, "Accessory proteins assist exonuclease-deficient bacteriophage T4 DNA polymerase in replicating past an abasic site," Biochemical Journal, vol. 402, no. 2, pp. 321-329, 2007.

[92] D. T. Minnick, M. Astatke, C. M. Joyce, and T. A. Kunkel, "A thumb subdomain mutant of the large fragment of Escherichia coli DNA polymerase I with reduced DNA binding affinity, processivity, and frameshift fidelity," Journal of Biological Chemistry, vol. 271, no. 40, pp. 24954-24961, 1996.

[93] K. Hashimoto, K. Shimizu, N. Nakashima, and A. Sugino, "Fidelity of DNA polymerase d holoenzyme from Saccharomyces cerevisiae: the sliding clamp proliferating cell nuclear antigen decreases its fidelity," Biochemistry, vol. 42, no. 48, pp. 14207-14213, 2003.

[94] S. S. Daube, G. Tomer, and Z. Livneh, "Translesion replication by DNA polymerase $\delta$ depends on processivity accessory proteins and differs in specificity from DNA polymerase $\beta$," Biochemistry, vol. 39, no. 2, pp. 348-355, 2000.

[95] C. A. Wu, N. J. Nelson, D. J. McGeoch, and M. D. Challberg, "Identification of herpes simplex virus type 1 genes required for origin-dependent DNA synthesis," Journal of Virology, vol. 62, no. 2, pp. 435-443, 1988.

[96] S. W. Wong, A. F. Wahl, P. M. Yuan et al., "Human DNA polymerase alpha gene expression is cell proliferation 
dependent and its primary structure is similar to both prokaryotic and eukaryotic replicative DNA polymerases," EMBO Journal, vol. 7, no. 1, pp. 37-47, 1988.

[97] D. J. M. Purifoy, R. B. Lewis, and K. L. Powell, "Identification of the herpes simplex virus DNA polymerase gene," Nature, vol. 269, no. 5629, pp. 621-623, 1977.

[98] A. I. Marcy, D. R. Yager, and D. M. Coen, "Isolation and characterization of herpes simplex virus mutants containing engineered mutations at the DNA polymerase locus," Journal of Virology, vol. 64, no. 5, pp. 2208-2216, 1990.

[99] C. W. Knopf, "Evolution of viral DNA-dependent DNA polymerases," Virus Genes, vol. 16, no. 1, pp. 47-58, 1998.

[100] J. T. Jofre, P. A. Schaffer, and D. S. Parris, "Genetics of resistance to phosphonoacetic acid in strain KOS of herpes simplex virus type 1," Journal of Virology, vol. 23, no. 3, pp. 833-836, 1977.

[101] M. Falkenberg, I. R. Lehman, and P. Elias, "Leading and lagging strand DNA synthesis in vitro by a reconstituted herpes simplex virus type 1 replisome," Proceedings of the National Academy of Sciences of the United States of America, vol. 97, no. 8, pp. 3896-3900, 2000.

[102] A. I. Marcy, P. D. Olivo, M. D. Challberg, and D. M. Coen, "Enzymatic activities of overexpressed herpes simplex virus DNA polymerase purified from recombinant baculovirusinfected insect cells," Nucleic Acids Research, vol. 18, no. 5, pp. 1207-1215, 1990.

[103] K. W. Knopf, "Properties of herpes simplex virus DNA polymerase and characterization of its associated exonuclease activity," European Journal of Biochemistry, vol. 98, no. 1, pp. 231-244, 1979.

[104] J. Gottlieb, A. I. Marcy, D. M. Coen, and M. D. Challberg, "The herpes simplex virus type 1 UL42 gene product: a subunit of DNA polymerase that functions to increase processivity," Journal of Virology, vol. 64, no. 12, pp. 59765987, 1990.

[105] M. L. Gallo, D. H. Jackwood, M. Murphy, H. S. Marsden, and D. S. Parris, "Purification of the herpes simplex virus type 1 65-kilodalton DNA-binding protein: properties of the protein and evidence of its association with the virusencoded DNA polymerase," Journal of Virology, vol. 62, no. 8, pp. 2874-2883, 1988.

[106] J. J. Crute and I. R. Lehman, "Herpes simplex-1 DNA polymerase. Identification of an intrinsic 5 ' $\rightarrow 3$ ' exonuclease with ribonuclease $\mathrm{H}$ activity," Journal of Biological Chemistry, vol. 264, no. 32, pp. 19266-19270, 1989.

[107] T. R. Hernandez and I. R. Lehman, "Functional interaction between the herpes simplex-1 DNA polymerase and UL42 protein," Journal of Biological Chemistry, vol. 265, no. 19, pp. 11227-11232, 1990.

[108] M. L. Gallo, D. I. Dorsky, C. S. Crumpacker, and D. S. Parris, "The essential 65-kilodalton DNA-binding protein of herpes simplex virus stimulates the virus-encoded DNA polymerase," Journal of Virology, vol. 63, no. 12, pp. 50235029, 1989.

[109] H. J. Zuccola, D. J. Filman, D. M. Coen, and J. M. Hogle, “The crystal structure of an unusual processivity factor, herpes simplex virus UL42, bound to the $\mathrm{C}$ terminus of its cognate polymerase," Molecular Cell, vol. 5, no. 2, pp. 267-278, 2000.

[110] T. S. R. Krishna, X.-P. Kong, S. Gary, P. M. Burgers, and J. Kuriyan, "Crystal structure of the eukaryotic DNA polymerase processivity factor PCNA," Cell, vol. 79, no. 7, pp. 1233-1244, 1994.

[111] J. Gottlieb and M. D. Challberg, "Interaction of herpes simplex virus type 1 DNA polymerase and the UL42 accessory protein with a model primer template," Journal of Virology, vol. 68 , no. 8, pp. 4937-4945, 1994.

[112] B. Roizman and M. Tognon, "Restriction endonuclease patterns of herpes simplex virus DNA: application to diagnosis and molecular epidemiology," Current Topics in Microbiology and Immunology, vol. 104, pp. 273-286, 1983.

[113] B. Roizman and T. Buchman, "The molecular epidemiology of herpes simplex viruses," Hospital Practice, vol. 14, no. 1, pp. 94-104, 1979.

[114] E. Kudo, H. Shiota, T. Naito, K. Satake, and M. Itakura, "Polymorphisms of thymidine kinase gene in herpes simplex virus type 1: analysis of clinical isolates from herpetic keratitis patients and laboratory strains," Journal of Medical Virology, vol. 56, no. 2, pp. 151-158, 1998.

[115] D. S. Parris and J. E. Harrington, "Herpes simplex virus variants resistant to high concentrations of acyclovir exist in clinical isolates," Antimicrobial Agents and Chemotherapy, vol. 22, no. 1, pp. 71-77, 1982.

[116] Y. T. Hwang, B. U.-Y. Liu, D. M. Coen, and C. B. C. Hwang, "Effects of mutations in the exo III motif of the herpes simplex virus DNA polymerase gene on enzyme activities, viral replication, and replication fidelity," Journal of Virology, vol. 71, no. 10, pp. 7791-7798, 1997.

[117] J. D. Hall, K. L. Orth, K. L. Sander, B. M. Swihart, and R. A. Senese, "Mutations within conserved motifs in the 3'-5' exonuclease domain of herpes simplex virus DNA polymerase," Journal of General Virology, vol. 76, no. 12, pp. 2999-3008, 1995.

[118] J. S. Gibbs, K. Weisshart, P. Digard, A. DeBruynkops, D. M. Knipe, and D. M. Coen, "Polymerization activity of an $\alpha$ like DNA polymerase requires a conserved 3'-5' exonuclease active site," Molecular and Cellular Biology, vol. 11, no. 9, pp. 4786-4795, 1991.

[119] F. J. P. Kühn and C. W. Knopf, "Herpes simplex virus type 1 DNA polymerase: mutational analysis of the 3'-5'exonuclease domain," Journal of Biological Chemistry, vol. 271, no. 46, pp. 29245-29254, 1996.

[120] C. Jiang, G. Komazin-Meredith, W. Tian, D. M. Coen, and C. B. C. Hwang, "Mutations that increase DNA binding by the processivity factor of herpes simplex virus affect virus production and DNA replication fidelity," Journal of Virology, vol. 83, no. 15, pp. 7573-7580, 2009.

[121] C. Jiang, Y. T. Hwang, J. C. W. Randell, D. M. Coen, and C. B. C. Hwang, "Mutations that decrease DNA binding of the processivity factor of the herpes simplex virus DNA polymerase reduce viral yield, alter the kinetics of viral DNA replication, and decrease the fidelity of DNA replication," Journal of Virology, vol. 81, no. 7, pp. 3495-3502, 2007.

[122] J. E. Reardon and T. Spector, "Herpes simplex virus type 1 DNA polymerase. Mechanism of inhibition by acyclovir triphosphate," Journal of Biological Chemistry, vol. 264, no. 13, pp. 7405-7411, 1989.

[123] R. O. Baker and J. D. Hall, "Impaired mismatch extension by a herpes simplex DNA polymerase mutant with an editing nuclease defect," Journal of Biological Chemistry, vol. 273, no. 37, pp. 24075-24082, 1998.

[124] F. Bogani and P. E. Boehmer, "The replicative DNA polymerase of herpes simplex virus 1 exhibits apurinic/apyrimidinic and 5'-deoxyribose phosphate lyase activities," Proceedings of the National Academy of Sciences of the United States of America, vol. 105, no. 33, pp. 11709-11714, 2008.

[125] W. Tian, Y. T. Hwang, Q. Lu, and C. B. C. Hwang, "Finger domain mutation affects enzyme activity, DNA replication efficiency, and fidelity of an exonuclease-deficient DNA 
polymerase of herpes simplex virus type 1," Journal of Virology, vol. 83, no. 14, pp. 7194-7201, 2009.

[126] W. Tian, Y. T. Hwang, and C. B. C. Hwang, "The enhanced DNA replication fidelity of a mutant herpes simplex virus type 1 DNA polymerase is mediated by an improved nucleotide selectivity and reduced mismatch extension ability," Journal of Virology, vol. 82, no. 17, pp. 8937-8941, 2008. 

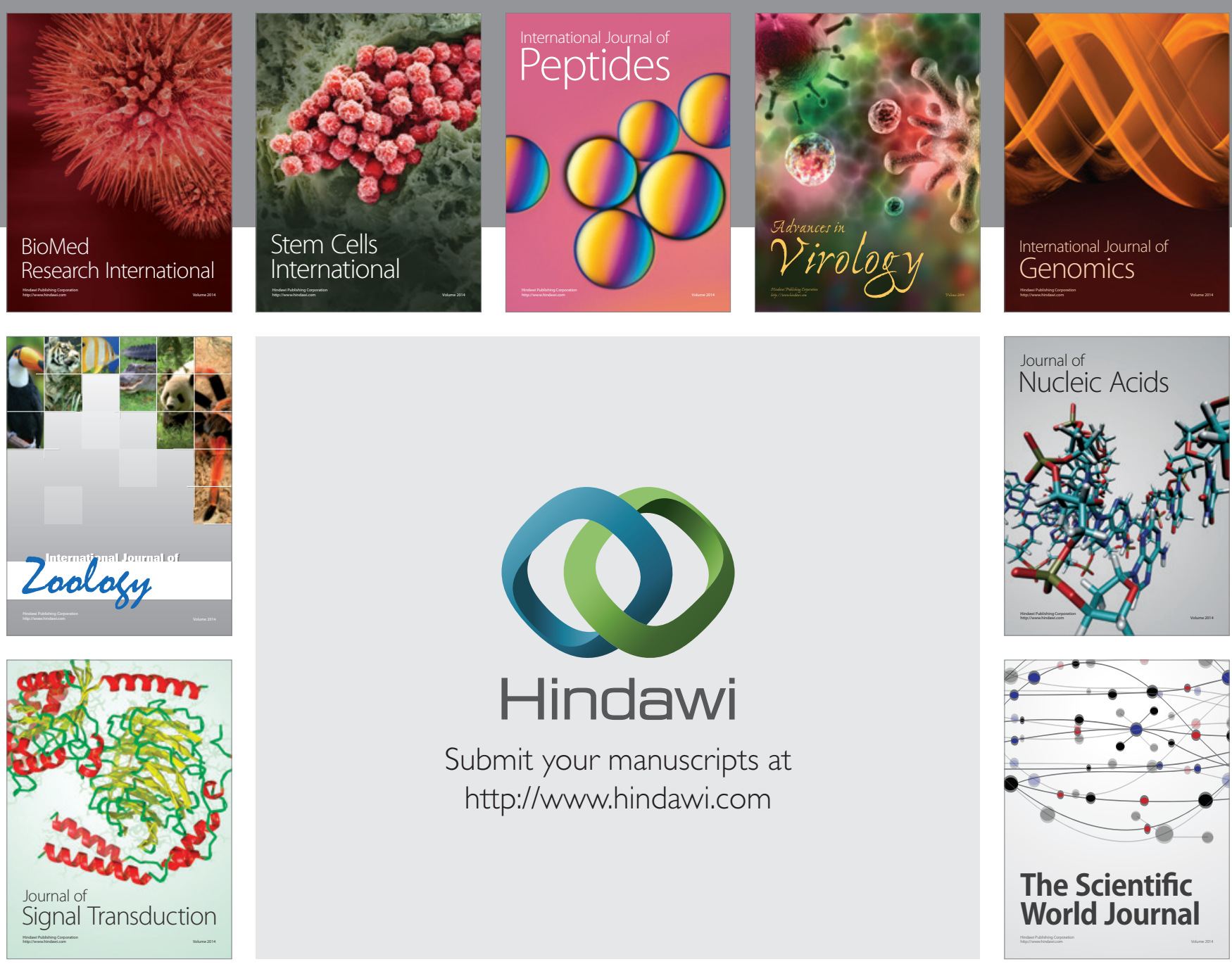

Submit your manuscripts at

http://www.hindawi.com
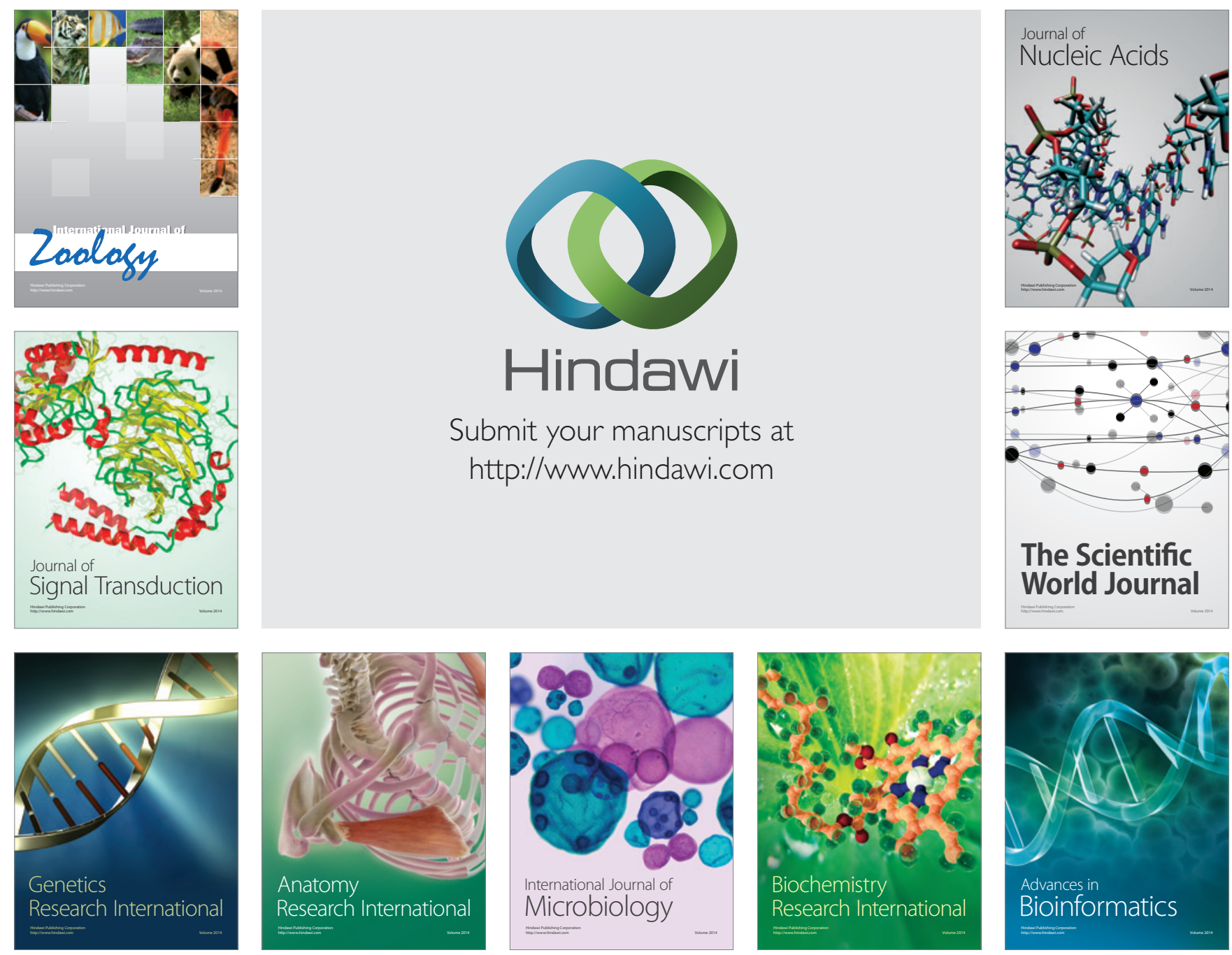

The Scientific World Journal
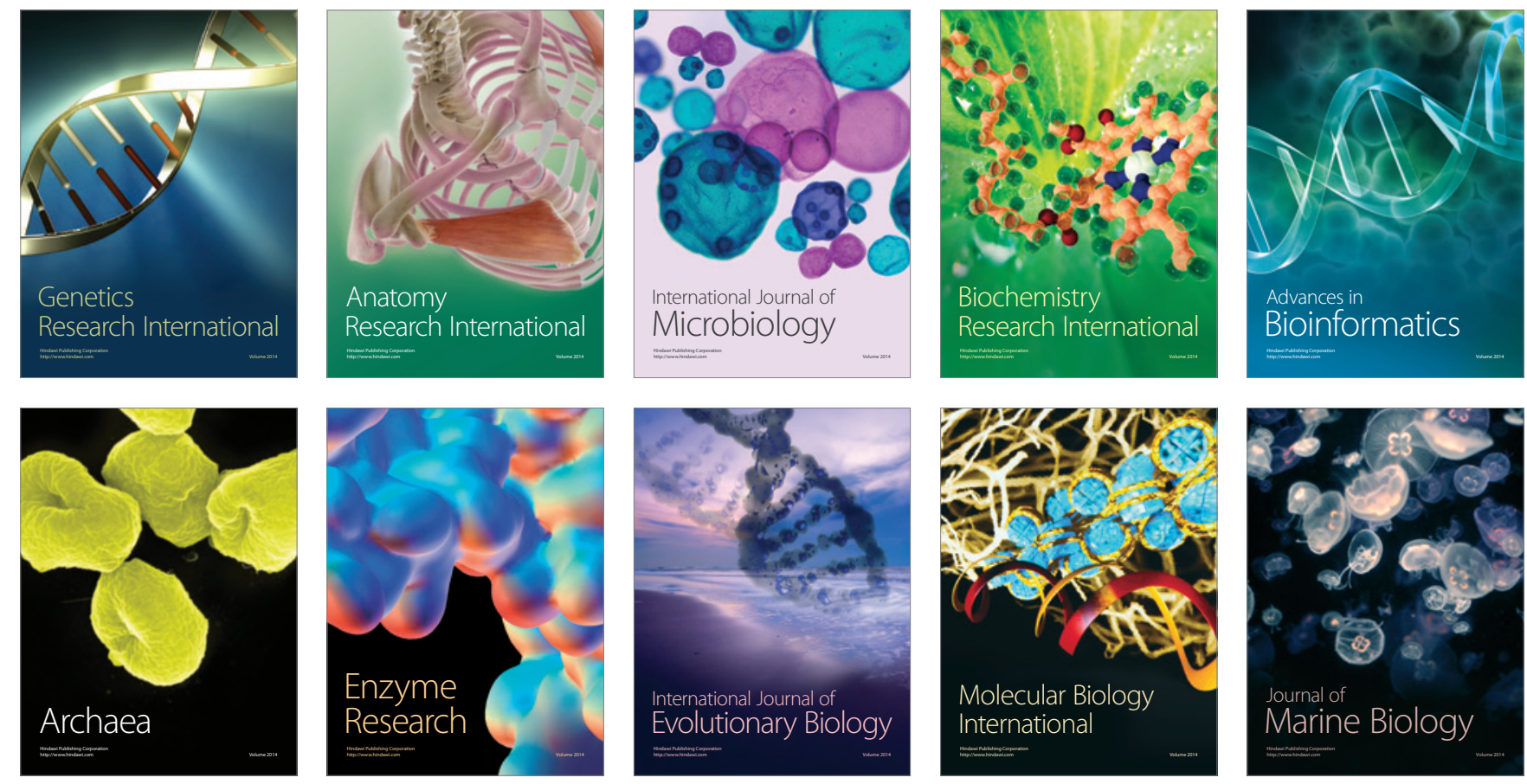